Marquette University

e-Publications@Marquette

Finance Faculty Research and Publications

Finance, Department of

4-1-2014

Differential Impacts of Structural and Cyclical Unemployment on Mortgage Default and Prepayment

Roberto G. Quercia

University of North Carolina at Chapel Hill

Anthony Pennington-Cross

Marquette University, anthony.pennington-cross@marquette.edu

Chao Yue Tian

University of North Carolina at Chapel Hill

Journal of Real Estate Finance and Economics (April 2014). DOI.

Shareable Link. Provided by the Springer Nature SharedIt content-sharing initiative. 


\title{
Differential Impacts of Structural and Cyclical Unemployment on Mortgage Default and Prepayment
}

\author{
Roberto G. Quercia \\ University of North Carolina at Chapel Hill, Chapel Hill, NC 27599 \\ Phone: (919) 843-2493 Fax: (919) 843-2080 \\ quercia@email.unc.edu \\ Anthony Pennington-Cross \\ Marquette University, Milwaukee, WI 5301-1881 \\ Phone: (414) 288-1452 Fax: (414) 288-5756 \\ anthony.pennington-cross@ marquette.edu \\ Chao Yue Tian \\ University of North Carolina at Chapel Hill, Chapel Hill, NC 27599 \\ Phone: (919) 843-0544 Fax: (919) 843-2080 \\ tianc@email.unc.edu
}




\begin{abstract}
The Great Recession (fourth quarter of 2007 through the second quarter of 2009) has been characterized by high rates of foreclosures and unemployment. Using a sample of community reinvestment loans, we examine the impact of structural or long term unemployment and cyclical or short term unemployment on mortgage terminations (default and prepayment). We find that mortgage default and prepayment are more sensitive to structural unemployment than cyclical unemployment. In addition, depending on whether structural unemployment is high or low, borrowers and lenders react differently to the incentives to terminate a loan.
\end{abstract}

JEL Codes: D12; G21; R22 


\section{Introduction}

The Great Recession and its slow recovery changed in the first quarter of 2009 from one driven by the boom and bust of the subprime market to one driven by worsening employment conditions. Since employment is a precondition for most households to meet their financial obligations, a weak labor market should increase mortgage default. Often used as a proxy for adverse trigger events (negative income shocks), the unemployment rate has indeed been found to be positively associated with mortgage delinquency (Campbell and Dietrich 1983), mortgage default (Capozza, Kazarian, and Thomson 1997, Deng, Quigley, and Van Order 2000, and Pennington-Cross and Ho 2010), and mortgage foreclosure (Elmer and Seelig 1999), and negatively associated with mortgage prepayment (Campbell and Dietrich 1983 and Deng, Quigley, and Van Order 2000).

While both theory and empirical evidence suggest that unemployment will increase the likelihood of mortgage default, there are few studies that address the pattern of such an impact. Within business cycle theory, unemployment can be viewed as a combination of a permanent component and a cyclical component. Unemployment caused by long term mismatches between labor supply and demand is often referred to as permanent or structural unemployment while cyclical unemployment is associated with temporary labor market conditions. Those components may have distinct patterns of movement and statistical properties (Mocan 1999), and thus, their impacts on mortgage performance may differ as well. Depending on how long a homeowner expects to be unemployed, the incentives for him to avoid mortgage delinquency and default should also differ. For 
example, expectations of a short duration of unemployment might inspire the homeowner to avoid foreclosure by accessing other financial assets (such as, savings or assistance from other family members). In contrast, if the spell of unemployment is expected to be very long, then these assets may be better used to cover the costs of moving to a location with superior labor market conditions or covering other consumer or financial needs (for example, food and transportation costs). In addition, the behavior of the lender/servicer likely will vary depending on perceptions of the length of the unemployment spell. From a policy and macro perspective, given the central role of unemployment and mortgage defaults in the sluggish recovery from the Great Recession, it makes sense to pursue a better understanding of the role that different types of unemployment rates play on mortgage default and prepayment.

In this paper, we explore the relationship between mortgage performance (mortgage default and prepayment) and different measures of unemployment using a sample of Community Reinvestment loans originated between 1991 and 2007. More narrowly, we use the Beveridge-Nelson (BN) decomposition (Beveridge and Nelson 1981) and the Hodrick-Prescott (HP) filter (Hodrick and Prescott 1997) as decomposition alternatives to separate the cyclical and permanent components of local unemployment rates. We find that permanent unemployment is a more important determinant of mortgage terminations than cyclical unemployment. Mortgages are most sensitive to changes in permanent unemployment defined by the HP filter. Predictions about future foreclosures that rely, even in part, on observed unemployment rates are likely to differ depending on the 
magnitude of the cyclical and permanent components.

The remainder of the paper is divided into four sections. The next section discusses the business cycle and the unemployment decomposition alternatives, followed by a description of the empirical strategy and the data. Finally, the empirical findings and their implications are presented.

\section{Unemployment and the Business Cycle}

A seasonally adjusted time series $y$ can be viewed as the combination of a permanent component and a cyclical component as follows

$$
y_{t}=c_{t}+\tau_{t}
$$

Where $c$ is the cyclical component (this is also referred to as the transitory, temporary, or short term component) and $\tau$ is the structural component (this is also referred to as the

trend, permanent, or long term component). Numerous approaches have been proposed to separate the cyclical component and the structural component in equation (1) (for a review, see Ozyildirim and Zarnowitz 2006) including the unobserved component approach (Harvey 1985), the BN decomposition, the HP filter, and the Band-pass filter (Baxter and King 1999). 
These approaches are based on a number of assumptions about features of the permanent and cyclical components that can lead to different decomposition results. For example, as applied to unemployment, the estimated structural component using the $\mathrm{BN}$ decomposition is often much closer to observed unemployment than that estimated using the HP filter. This is because the BN decomposition assumes correlated structural and cyclical components while the HP filter imposes a smooth shape on the long term unemployment rate. Another example is in the difference between the $\mathrm{BN}$ decomposition and the unobserved component approach. The unobserved component approach proposed by Harvey imposes a zero correlation between the structural component and cyclical component. Morley, Nelson, and Zivot (2003) and Sinclair (2009) introduce correlation in the structural models.

The least empirically complicated decomposition technique is the linear deterministic trend approach. However, this approach is not theoretically or empirically sound when the series is not stationary (Stock and Watson 1988). The existence of a unit root process indicates that a series is not stationary. Many tests have been designed to detect unit roots in time series including Dickey and Fuller (1981), Perron and Phillips (1988), and Perron (1989). We perform the Augmented Dickey-Fuller tests on the unemployment rates between 1990 and 2009 for 540 different counties in the US. The results show that among the 540 counties examined, test statistics reject a unit root process at the 10 percent level for only 12 counties. The same tests reject a unit root process of the first difference of unemployment rates for 534 counties. Table 1 presents the Augmented Dickey-Fuller test 
results for the US unemployment rate (seasonally adjusted) and its first difference. It shows the US unemployment rate is an I(1) process (unit root in the level but not in the first difference). ${ }^{1}$ These results, combined with the fact that the test statistic is sensitive to de-trending techniques, indicates that it is necessary to examine decomposition techniques that do not require a series to be stationary. Hence, this paper uses the BN decomposition and the HP filter as two alternative de-trending techniques. The BN decomposition requires a series to be stationary in the difference and the HP filter does not require the series to be stationary.

Insert Table 1 here.

\section{A. BN Decomposition}

The first difference of the non-stationary series $y$ in equation (1) is $w . w$ is stationary and it can be expressed as follows

$$
w_{t}=\mu+\varepsilon_{t}+\phi_{1} \varepsilon_{t-1}+\ldots
$$

Where $\mu$ is the expectation of $w$ and $\varepsilon_{t}$ is the uncorrelated disturbance term. Beveridge and Nelson (1981) show that the structural component can be expressed as:

$$
\tau_{t}=y+\left(\sum_{1}^{\infty} \phi_{i}\right) \varepsilon_{t}+\left(\sum_{2}^{\infty} \phi_{i}\right) \varepsilon_{t-1}+\ldots
$$

and the cyclical component,$c_{t}$, is $\left(\sum_{1}^{\infty} \phi_{i}\right) \varepsilon_{t}+\left(\sum_{2}^{\infty} \phi_{i}\right) \varepsilon_{t-1}+\ldots$ 


\section{B. HP Filter}

The HP filter assumes the structural component, $\tau_{t}$, in equation (1) is smooth over time and is estimated by solving the following equation. ${ }^{2}$

$$
\min _{\left\{\tau_{t}\right\}}\left\{\sum_{t} c_{t}^{2}+\kappa \sum_{t}\left[\left(\tau_{t}-\tau_{t-1}\right)-\left(\tau_{t-1}-\tau_{t-2}\right)\right]^{2}\right\}
$$

Where $\kappa$ determines how smooth the time series of $\tau_{t}$ is and larger values of $\kappa$ correspond to more smooth time series.

\section{Empirical Strategy and Data}

To examine the relationship between local unemployment rates and loan performance, we estimate a competing risk approach and follow the empirical strategy used by Deng, Quigley, and Van Order (2000), McCall (1996), and Pennington-Cross and Ho (2010).

\section{A. Survival and Hazard Specification}

Under the competing risk framework, loan default and prepayment are jointly modeled while addressing the data censoring issue. The estimation relies on the construction of the hazard and the survival functions, which are introduced as follows.

Let $\lambda_{i}^{r}$ be the hazard rate of default $(r=D)$ or prepayment $(r=P)$ for loan $i$. The 
hazard is specified as:

$\lambda_{i}^{r}\left(t \mid X_{i}(t), \theta_{D}, \theta_{P}\right)=\exp \left(\lambda_{0}^{r}(t)+X_{i}(t) * \beta_{r}+\theta_{r}\right)$

where $\lambda_{0}^{r}$ is the baseline hazard, $X_{i}(t)$ is a matrix of risk determinants that may or may not vary over time $t, \beta_{r}$ are the risk determinate parameters to be estimated, and $\theta_{r}$ are the heterogeneity parameters to be estimated which are assumed to be independent of observed characteristics. The prepayment and default events are assumed to be independent and the corresponding survival function $S_{i}$ is defined as:

$$
\begin{aligned}
& S_{i}\left(t \mid X_{i}(t), \theta_{D}, \theta_{P}\right) \\
& =\exp \left(-\int_{0}^{t}\left[\lambda_{i}^{D}\left(s \mid X_{i}(t), \theta_{D}, \theta_{P}\right)+\lambda_{i}^{P}\left(s \mid X_{i}(t), \theta_{D}, \theta_{P}\right)\right] d s\right)
\end{aligned}
$$

The log likelihood, $L L$, is expressed in discrete time assuming risk determinants are constant within each time interval.

$$
L L=\sum_{\text {uncensored }} \log \lambda_{i}^{r}\left(t \mid X_{i}(t), \theta_{D}, \theta_{P}\right)+\sum_{\text {all }} \log S_{i}\left(t \mid X_{i}(t), \theta_{D}, \theta_{P}\right)
$$

The baseline hazard is estimated using local regression, as motivated by Cleveland (1979) and others, to smooth the Kaplan-Meier hazards of prepayment and default. Let $n_{t}$ be the population at time $t$ and $n_{r t}$ be the number of termination events of type $r$ at time $t$. The Kaplan-Meier hazard for time $t$ and termination type $r$ is $n_{r t} / n_{t}$. 
The smoothing parameters are set to maximize the Akaike Information Criteria (AIC), 0.32 for default and 0.27 for prepayment. Default is defined as the first month with an observed 90-day delinquency on a mortgage and prepayment as the month in which the loan is paid off prematurely. The specification of heterogeneity mass point $p_{m}$ for group $m$, is defined in a logistic transformation to bound the probabilities between zero and one.

$$
p_{m}=\frac{e^{q_{m}}}{\sum_{m} e^{q_{m}}}
$$

where $q_{m} \in(-\infty,+\infty)$ and $q_{l}$ is normalized to 0 .

\section{B. Local Unemployment Rate and Decomposition}

Local area unemployment data from the Bureau of Labor Statistics provide unemployment information for each county and each series is seasonally adjusted using the Census X11 method.

The implementation of BN decomposition follows Newbold (1990). Assume that $w_{t}$ in equation (2) follows an $\operatorname{ARMA}(p, q)$ process and let $\phi_{1}$ through $\phi_{p}$ be the AR parameters.

Let $\hat{w}_{t}(j)$ be the forecast of $w_{j}$ at time $t$, and $\bar{w}$ is the mean of the forecast. The cyclical component is defined as follows: 


$$
c_{t}=\sum_{j=1}^{q}\left(\hat{w}_{t}(j)-\bar{w}\right)+\left(1-\sum_{1}^{p} \phi_{i}\right)^{-1} \sum_{j=1}^{p} \sum_{i=j}^{p}\left[\phi_{i}\left(\hat{w}_{t}(q-j+1)-\bar{w}\right)\right]
$$

We need to determine a forecasting process for each of the 540 counties covered in the data. Since we are trying to find patterns for over 500 series, we rely on the Bayesian Information Criteria (BIC) or Schwarz criteria to determine the Auto-Regressive and Moving Average (ARMA) process. Each series allows for up to $\operatorname{ARMA}(4,4)$ with the default being AR(1). ${ }^{3} \quad$ The Schwarz criteria tend to select lower order ARMA processes. 129 counties are determined to be $\operatorname{ARMA}(1,0)$ during the sample period. A summary of the ARMA process selected for each county is presented in Table 2.

Insert Table 2 here.

The BN decomposition may be sensitive to the potentially less precise forecasting mentioned above as well as the extreme value in $\left(1-\sum_{1}^{p} \phi_{i}\right)^{-1}$ in equation (9). As a result, extreme values of the cyclical component are dropped from the analysis. Approximately 10 percent of the counties and observations have extreme values. Estimation results are not affected when we set the extreme cyclical component to zero, which indicates our results are reasonably robust.

Since the analysis is done at the monthly frequency, the smoothing parameter for the HP 
filter is set to be 129,600 following Ravn and Uhlig (2002). ${ }^{4}$ As an example, Figure 1 illustrates the seasonally adjusted US unemployment rate and the $\mathrm{BN}$ and the HP structural components of the observed seasonally adjusted US unemployment rate.

Insert Figure 1 here.

Given that HP components estimated in the past are affected each time the data is extended, we create a separate measure based on the HP structural component ranking for a robustness check. Each month we rank counties according to the HP structural component from low rate to high. The higher the ranking (or "score"), the higher the relative HP structural component is. We then sum the ranking of all months within our sample period. Therefore, the final "score," or HP Ranking Score (HPRS), can be interpreted as a measure of how consistently the HP structural component is higher than that in other counties.

The relationship between the business cycle, local unemployment, and loan performance is examined in a later section in a series of experiments. Using the default and prepayment hazards coefficient estimates, probabilities are simulated to investigate the response to changes in the observed and permanent components of the local unemployment rate. 


\section{Community Reinvestment Loans}

The data for the analysis come from a national sample of community reinvestment loans. ${ }^{5}$ The database contains information on approximately 46,000 loans originated to low- or moderate-income families that reside in low-income areas, minority areas regardless of family income, or any minority borrower regardless of income or location.

The analysis sample includes 30-year fixed rate home purchase loans originated in 1991 or later, excluding manufactured homes. Over 22,000 loans in 540 counties throughout the country have complete loan and borrower information. The hazard analysis is performed on a monthly basis for loan history (loan age) up to 120 months. A summary of the loans by year of origination is presented in Table 3.

Insert Table 3 here.

The Kaplan-Meier hazards and local regressions for default and prepayment (Figures 2 and 3 respectively) show distinct patterns of mortgage termination. The conditional monthly default hazard rate reaches a high of approximately 0.3 percent at about three years after loan origination and lingers with a slow upward trend even at around ten years after loan origination. The prepayment hazard rate reaches a high of approximately 1.2 percent at two and half years after loan origination and continues to be high until five years after loan origination.

Insert Figure 2 here. 
Insert Figure 3 here.

Table 4 includes a list of the explanatory variables and their definitions. The variables are grouped into those only observed at origination and those observed repeatedly over the life of the loan. The annual income normalized by the area median income (inc_ami) is used to test whether the relative income of the household makes it more susceptible to default or prepayment. However, low income in itself should not affect the probability that a loan prepays or defaults because it does not directly affect the value of the option to terminate the loan or the extent to which it is "in the money" to do so. The financial incentives should be driven by interest rates and home values. However, low income likely functions as a proxy for unobserved education, mobility, wealth, and transaction costs. Therefore, we anticipate that higher income will be associated with a lower probability of default and a higher probability of prepayment. Monthly mortgage debt payments normalized by borrower monthly income (debt to income ratio or $d t i$ ) is also included. We expect that households with larger debt burdens will be more likely to default and prepay because they will be more susceptible to unobserved trigger events that could cause a loan to terminate such as divorce, health events, or job loss. Through a similar logic, a higher borrower credit score at origination (fico) is expected to decrease the probability of default and increase the probability of prepayment. Moreover, borrowers who have not paid their prior debt obligations are also less likely to pay their current and future debt obligations. At the same time, poor credit history will also make it more difficult for a borrower to find alternative mortgage financing in the event of a move or a decline in interest rates. 
A high loan-to-value ratio is associated with higher probabilities of default (Kau, Keenan, and Kim 1994). cltv is estimated using the outstanding balance on the loan and an estimate of current house value generated through Federal Housing Finance Agency's metropolitan area house price index. A borrower's decision to terminate a loan is also influenced by expectations of future house prices, interest rates, and the length or cost of defaulting. We include three variables that will be discussed later in greater detail: a forecast of the future loan-to-value ratio (cltv12), a forecast of the future net present value percentage gain on a refinance (refil2), and a measure of number of days from the start of foreclosure proceedings to the day the property is referred for sale (fdays).

Insert Table 4 here.

Following Deng, Quigley, and Van Order (2000), a measure of the net present value gain from refinancing a fixed rate mortgage ( $r e f i$ ) is constructed as follows. At time $t$, the gain from refinancing is the percentage reduction in the discounted value of all future mortgage payments if the borrower refinances, $P V_{r}$, versus if the borrower continues to hold their current mortgage, $P V_{c}$ :

$r e f i_{t}=\left[\frac{P V_{c t}-P V_{r t}}{P V_{c t}}\right]$

where

$$
P V_{j t}=\sum_{m=0}^{R M T} \frac{P_{j t}}{\left(1+d_{t}\right)^{m}}
$$


Where $j=c, r, R M T$ is the remaining mortgage term in months, $d_{t}$, is the discount rate measured by the 30 -year fixed conventional mortgage rate collected from the federal reserve (reported by Freddie Mac), and

$P_{j t}=i_{j t} Q\left[\frac{\left(1+i_{j t}\right)^{R M T}}{\left(1+i_{j t}\right)^{R M T}-1}\right]$

where $i_{c t}$ is the market 30-year fixed mortgage interest rate at mortgage origination ${ }^{6}$ at time $t$ and $i_{r t}$ is the market 30-year fixed mortgage interest rate at time $t$. We expect prepayment hazards to increase with refi, as defined in equation 10 through 12 ..

We also include future interest and house price volatility measures, under the assumption that consumer expectations are rational and correctly forecast volatility. Interest rate volatility (varmrate) is the moving variance of future 24-month 30-year fixed-rate conventional mortgage rates and house price volatility (varhpi) is measured by the moving variance of future 24-month metropolitan area HPI. We expect that more volatility in interest rates will reduce refinance probabilities since borrowers may wait for interest rates to decline even further. Similarly, house price volatility increases the value of delaying default (Kau and Kim 1994 and Kau and Keenan 1995).

County unemployment rates are included to capture labor market conditions. Consistent with prior work, higher county unemployment rates indicate a higher probability that borrowers have lost their jobs or have a lower income stream, making it more difficult to make mortgage payments. Unemployment may also increase the use of "distressed" 
prepayments, but it also makes it harder to meet underwriting requirements to refinance. ${ }^{7}$ To investigate the different roles of long run vs. short run local unemployment on mortgage terminations, we include different measures of cyclical and structural unemployment (observed, BN and HP cyclical and structural components). The average observed county unemployment rate is approximately 5.4 percent. $^{8}$ Given the distressed nature of labor market it may be tempting to think that mortgage defaults may contribute to unemployment. Our empirical tests uses individual loan data. The employment status of an individual should have an undetectable impact on unemployment rates; therefore, unemployment rates can be treated as exogenous to mortgage status.

Finally, we control for the impact of local foreclosure laws by including the average number of days from the start of foreclosure proceedings to the day when the property is referred for sale (fdays) in each state. Cutts and Merrill (2008) estimate this number using Freddie Mac data. It can serve as a proxy for the amount of "free rent" that a household can expect to gain during the foreclosure process and the cost of foreclosure that the lender/investor will bear in the event of a default. Due to the interaction of the lender and borrower the direction of the impact is an open empirical question.

Table 4 provides summary statistics for variables included in the analysis. Compared with subprime loans reported by Pennington-Cross and Ho (2010), on average, our loans are observed for much longer, have higher credit scores at origination, and have relatively 
higher loan balances.

\section{Estimation Results}

\section{A. Baseline Results}

The results of the competing risk with heterogeneity analyses are presented in Tables 5 (default) and 6 (prepayment). Most of the estimates have signs consistent with expectations and are statistically significant.

Borrower income relative to the metropolitan area median, credit score at origination, current loan-to-value ratio, and local unemployment rate are all strong indicators of default and prepayment probabilities. Higher income and credit scores (the prior ability to pay financial obligations in a timely fashion) are negatively associated with default and positively associated with prepayment. Higher cltv is associated with higher default and lower prepayment probabilities. The variable refi is also a positive indicator for both default and prepayment. It is unclear why higher interest rates should drive up default probabilities in fixed rate loans; perhaps higher rates make competing household debt more costly, so that homeowners have a harder time paying the mortgage. As expected, we find that volatility in interest rates (varmrate) delays prepayment. However, we do not find that volatility in house prices (varhpi) delays default.

Berkovec, Canner, Gabriel, and Hannan (1998), Calem and Wachter (1999), and Deng 
and Gabriel (2006) find that the debt-to-income ratio (dti) has little impact on mortgage termination. In contrast, we find a strong link between front-end ratio and prepayment. However, after controlling for income, the debt-to-income ratio is generally insignificant in the default equations.

All local unemployment rate measures (unempr) other than Cyclical HP are positively associated with default and negatively associated with prepayment. The HP cyclical component does not influence mortgage default significantly. HP and BN cyclical components have a relatively small impact on mortgage terminations compared to the structural components. These results provide evidence that long run unemployment measures are a more important determinant of mortgage termination than cyclical unemployment. We show simulated default and prepayment risks with respect to changes in the observed unemployment rate and structural components (Structural HP, Structural BN) in Figures 4 and $5 .^{9}$

Insert Table 5 here.

Insert Table 6 here.

Insert Figure 4 here.

Insert Figure 5 here.

Figure 4 indicates that default probabilities are sensitive to the measure of structural unemployment used. The BN decomposition, by design, generates a structural component that is very close to the observed local unemployment rate. As a result the impact of the $\mathrm{BN}$ structural component on default and prepayment probabilities deviates very little 
from the impact of observed unemployment rates. In contrast, relative to observed rates, both default and prepayment are more sensitive to HP structural unemployment.

\section{B. Loan Termination Behavior and the Economic Environment}

To better understand the link between mortgage terminations and the permanent component and cyclical component of unemployment rates, we interact different measures of local unemployment with other explanatory variables in Tables 7 and 8.

Insert Table 7 here.

Insert Table 8 here.

Again, most of the single variable estimates have signs consistent with expectations and are statistically significant. For default, the interaction results are most consistent for the credit score (unempr_fico) and the equity position (unempr_cltv). Higher contemporaneous unemployment rates (whether measured by observed, cyclical components, or structural components) are all associated with an increase in default and prepayment sensitivity to credit scores at origination. This impact is illustrated in Figures 6 through 8 . We perform a number of simulations to demonstrate the impact of changes in the economic environment characterized by different unemployment measures. The hazards are simulated at the $37^{\text {th }}$ month (around the first peaks of defaults) with all other characteristics evaluated at their means. We compare roughly one standard deviation above and below the mean of local unemployment and set the two comparison points at 4 percent and 8 percent for the observed and structural component and at -1 and 1 percent unemployment rate for the cyclical component. Figure 6 indicates that higher 
unemployment, measured by the observed unemployment rate, is associated with a higher probability of default. Default is also more sensitive to the borrower's credit score when the observed unemployment rate is high. In contrast, Figure 7 indicates that the effect of the cyclical component is very similar to the impact of the observed unemployment rate. Therefore, we can conclude that the observed interactions between the labor market and credit quality on the mortgage market are caused by structural unemployment, not cyclical unemployment.

Insert Figure 6 here.

Insert Figure 7 here. Insert Figure 8 here.

Figures 9 through 12 conduct similar exercises and illustrate the interaction between various measures of unemployment and the equity position of the borrower (current LTV). Figure 9 illustrates that high observed unemployment rates are associated with a higher probability of default regardless of the equity position. In addition, high observed unemployment rates increased the sensitivity of default to the equity position. Once again, the impact of the cyclical unemployment components (Cyclical HP and Cyclical $\mathrm{BN}$ ) on default is smaller than the structural components (Structural HP) or the observed rate. $^{10}$

Insert Figure 9 here.

Insert Figure 10 here.

Insert Figure 11 here.

Insert Figure 12 here. 
In summary, borrowers use the default option more aggressively when long term unemployment is high. In addition, mortgages to borrowers with low credit scores are less able to survive periods with higher levels of structural, or long run, unemployment but are not differentially impacted by cyclical, or short run, unemployment.

Similar to the default results, in terms of prepayment, the interactions are most consistent for the option proxy, refi, and borrower credit scores, fico. In addition, the structural components tend to dominate the cyclical components of unemployment. Locations with high rates of structural unemployment, whether measure by $\mathrm{HP}$ or $\mathrm{BN}$, are also more sensitive to borrower credit history. In general, higher credit score borrowers are more likely to refinance or prepay the loan. When structural unemployment is high the relative difference between high and low credit score prepayment propensities is increased. However, a higher rate of structural unemployment depresses the responsiveness of borrowers to interest rates. Therefore, when labor market conditions are structurally weak, credit history becomes even more important for maintaining access to credit markets and borrowers are less able to refinance existing debt when interest rates decline.

\section{The Role of Expectations}

Next, we examine the impact of borrower expectations on mortgage terminations. We test three variables: a 12-month forecast of future loan-to-value ratio (cltv12), a 12-month forecast of the future percentage gain on refinance (refil2), and a measure of the number of days between a foreclosure referral and its referrer for sale in each state (fdays). The 
variable fdays is a proxy of the lenders costs of foreclosure and is largely determined by state regulations. It also proxies for how much "free rent" a delinquent borrower can gain while making no further mortgage payments.

The variable cltv12 is defined as the ratio of the estimated outstanding loan balance to the expected house value 12 months from the date of each observation. ${ }^{11}$ The outstanding loan balance is estimated according to the fixed rate amortization schedule for each loan and each period assuming the borrower stays current for the next 12 months. The expected house value is generated based on the metropolitan area house price index. A forecasting rule is generated on the stationary series and then forecasts of house value 12 months from the current period are generated for each loan and month. ${ }^{12}$ Similarly, the variable refil2 is generated based on a forecast of the market interest rate and remaining balance following the procedure described in equations (10) to (12).

The estimates are presented in Tables 9 (default) and 10 (prepayment). In the default model, we see cltv 12 is statistically significant and positive when combined with the cyclical (short term) unemployment rate and HPRS. Therefore, borrowers will be more likely to default if future house values are expected to decline. We do not get such effects in the long term unemployment rate (Structural HP and Structural BN) specifications. On the other hand, expectations of worsening equity positions (declining house prices) deter refinancing and prepayment even more regardless of the specification. 
Expectations of future interest rates had no additional impact on refinancing activity or prepayment. This result may indicate that borrowers are willing to exercise the prepayment option whenever it is in the money and the costs of refinancing may have become so low that there is little incentive for borrowers to wait for lower interest rates in the future.

Finally, we find that expectations about lender costs and borrower benefits, captured with foreclosure days (fdays), does not influence the whether loans default. These higher costs, however, do seem to make prepayment a more attractive option. Long foreclosure proceedings may give defaulting households enough time to find a buyer for the home; or incentivize lenders/investors to accept short sales (a sale of the property to extinguish the debt even if it does not cover all of the outstanding debt and accumulated fees from the delinquency) by increasing the cost of default.

Insert Table 9 here.

Insert Table 10 here.

\section{Serious Delinquency Vs. Short-Term Delinquency}

Finally, we conduct a preliminary investigation of short-term or 30-day delinquency patterns. We estimate a specification similar to the one presented in Table 9. The new default results are presented in Table 11. We focus our discussion on two variables: unempr and fdays. Both the cyclical and structural components of unemployment seem to 
be much stronger drivers of short-term delinquency than serious delinquency (90 days or more delinquent). Similarly, higher expected lender costs/borrower benefits (fdays) are associated with a higher incidence of short-term delinquency but are not associated with serious delinquency. This provides suggestive evidence that borrowers are aware of how long a foreclosure takes. In states where the foreclosure timeline is very long, borrowers should be less worried about losing the home and are more willing to be temporarily delinquent on their mortgage. In contrast, the foreclosure timeline has no impact on serious delinquency.

Insert Table 11 here.

\section{Conclusions}

In the wake of the recent economic crisis, many government programs, such as the Emergency Homeowners' Loan Program run by the Department of Housing and Urban Development) and the Hardest Hit Fund run by Department of Treasury and authorized under the Emergency Economic Stabilization Act of 2008, have been designed specifically to help homeowners avoid foreclosures. The local unemployment situation inevitably becomes an important criterion when targeting resources to deal with the crisis. While the observed local unemployment rate is an important determinant of mortgage termination, the long run or structural unemployment rate is a more important determinant of mortgage terminations. In contrast, short run or cyclical unemployment rates play a very small role. Therefore, any policy interventions will be more effective if they focus on locations with high structural unemployment. 
The way unemployment is measured also matters. Default and prepayment probabilities are more responsive to changes in the long run (structural) local unemployment rate when measured with the HP filter than when measured by changes in the observed local unemployment rate. The probability of mortgage default is much higher for households in areas where long term unemployment is high. In contrast, when the $\mathrm{BN}$ procedure is used there is little differential impact. Future work needs to explore this issue further.

We also find that the impacts of risk factors can vary significantly depending on the economic environment. For example, when structural unemployment rates are high, loans are more sensitive to the amount of equity in the home. In particular, homeowners default much more when long term or structural employment conditions are weak. This effect is not found for short term or cyclical employment conditions. In terms of the incentives to refinance, when structural employment conditions are weak households are even less responsive to declining interest rates. In addition, credit scores matter even more for both default and prepayment when structural unemployment is high. In short, while access to credit markets is greatly hampered by high rates of structural unemployment, the impact is softened for those with better credit histories.

We find expectations also affect mortgage outcomes. Expectations of higher lender foreclosure costs and longer free rent have no effect on serious delinquencies, but are associated with increased prepayments. One explanation is that the higher default costs may make the alternative option (prepayment) relatively less costly leading to more 
workouts and short sales. In contrast to the serious delinquency results, loans in states with longer free rent time lines are more likely to have short-term (30 days) delinquency than loans in more lender-friendly states. These results may reflect the recognition by borrowers that there is plenty of time to cure a loan with a modest amount of delinquency in a state with a longer foreclosure time line. These results may also shed some light on how borrowers will react to the lengthening of the foreclosure timeline for other reasons. For example, some lenders have imposed foreclosure moratoria due to an inability to process foreclosures and legal concerns over the documentation used during the foreclosure process.

In sum, this study provides empirical evidence of the link between long run or structural unemployment and mortgage termination through default and prepayment. The results indicate that if attempts to intervene in the labor market are to have meaningful impacts on mortgage markets, the intervention should be targeted at long term or structural components of local unemployment. 


\section{References}

Baxter, Marianne, and Robert G. King. 1999. Measuring Business Cycles: Approximate Band-Pass Filters For Economic Time Series. The Review of Economics and Statistics 81(4): 575-593.

Berkovec, James A., Glenn B. Canner, Stuart A. Gabriel, and Timothy H. Hannan. 1998. Discrimination, Competition, and Loan Performance in FHA Mortgage Lending. Review of Economics and Statistics, 80(2) 241-250.

Beveridge, Stephen, and Charles R. Nelson. 1981. A New Approach to Decomposition of Economic Time Series into Permanent and Transitory Components with Particular Attention to Measurement of the 'Business Cycle'. Journal of Monetary Economics 7(2): 151-174.

Calem Paul S. and Susan M. Wachter. 1999. Community Reinvestment and Credit Risk: Evidence from an Affordable-Home-Loan Program. Real Estate Economics, 27 (1): 105-134.

Campbell, Tim S., and J. Kimball Dietrich. 1983. The Determinants of Default on Insured Conventional Residential Mortgage Loans. The Journal of Finance 38(5): 15691581.

Capozza, Dennis R., Dick Kazarian, and Thomas A. Thomson. 1997. Mortgage Default in Local Markets. Real Estate Economics 25(4): 631-655.

Clements, Michael P., Fred Joutz, and Herman O. Stekler. 2007. An evaluation of the forecasts of the federal reserve: a pooled approach. Journal of Applied Econometrics, 22(1), 121-136. 
Cleveland, William S. 1979. Robust Locally-Weighted Regression and Smoothing Scatterplots. Journal of the American Statistical Association 74: 829-836.

Cutts, Amy C. and William A. Merrill. 2008. Interventions in Mortgage Default:

Policies and Practices to Prevent Home Loss and Lower Costs. Borrowing to Live: Consumer and Mortgage Credit Revisited, eds. N. P. Retsinas and E. S. Belsky, Brookings Institution Press, Washington, DC.

Deng, Yongheng, John M. Quigley, and Robert Van Order. 2000. Mortgage Terminations, Heterogeneity and the Exercise of Mortgage Options. Econometrica 68(2): 275-307.

Deng, Yongheng and Stuart A. Gabriel. 2006. Risk-Based Pricing and the Enhancement of Mortgage Credit, Availability among Underserved and Higher CreditRisk Populations. Journal of Money, Credit, and Banking, 38(6): 1431-1460

Dickey, David A., and Wayne A. Fuller. 1981. Likelihood Ratio Statistics for Autoregressive Time Series with a Unit Root. Econometrica 49(4): 1057-72.

Elmer, Peter J., and Steven A. Seelig. 1999. Insolvency, Trigger Events, and Consumer Risk Posture in the Theory of Single-Family Mortgage Default. Journal of Housing Research 10(1): 1-25.

Harvey, A. C. 1985. Trends and Cycles in Macroeconomic Time Series. Journal of Business \& Economic Statistics 3(3): 216-27.

Hodrick, Robert J., and Edward C. Prescott. 1997. Postwar U.S. Business Cycles: An Empirical Investigation. Journal of Money, Credit and Banking 29(1): 1-16.

Kau, James B., Donald C. Keenan, and Taewon Kim. 1994. Default Probabilities for 
Mortgages. Journal of Urban Economics 35 (3): 278-296.

Kau, James, and Kim, Taewon. 1994. Waiting to Default: The Value of Delay. Journal of American Real Estate and Urban Economics Association 22 (3): 539-51.

Kau, James, and Donald Keenan. 1995. An Overview of the Option-Theoretic Pricing of Mortgages. Journal of Housing Research 6 (2): 217-244.

McCall, Brian P. 1996. Unemployment Insurance Rules, Joblessness, and Part-Time Work. Econometrica 64(3): 647-682.

Mocan, H. Naci. 1999. Structural Unemployment, Cyclical Unemployment, and Income Inequality. The Review of Economics and Statistics 81(1): 122-134.

Morley, James C., Charles R. Nelson, and Eric Zivot. 2003. Why Are the BeveridgeNelson and Unobserved-Components Decompositions of GDP So Different? The Review of Economics and Statistics 85(2): 235-243.

Newbold, Paul. 1990. Precise and Efficient Computation of the Beveridge-Nelson Decomposition of Economic Time Series. Journal of Monetary Economics 26(3): 453457.

Pennington-Cross, Anthony and Giang Ho. 2010. The Termination of Subprime Hybrid and Fixed Rate Mortgages. Real Estate Economics 38(3): 399-426.

Perron, Pierre. 1989. The Great Crash, the Oil Price Shock, and the Unit Root Hypothesis. Econometrica 57(6): 1361-1401.

Perron, Pierre, and Peter C. B. Phillips. 1988. Testing for a Unit Root in Time Series Regression. Biometrika 75(2): 335-346. 
Ravn, Morten O., and Harald Uhlig. 2002. On Adjusting the Hodrick-Prescott Filter for the Frequency of Observations. The Review of Economics and Statistics 84(2): 371375.

Quercia, Roberto G., Sarah F. Riley, and HongYu Ru. 2009. Community Advantage Program Database: Overview and Generalization. Cityscape, 11(3).

Sinclair, Tara M. 2009. The Relationships between Permanent and Transitory Movements in U.S. Output and the Unemployment Rate. Journal of Money, Credit and Banking 41(2-3): 529-542.

Stock, James H., and Mark W. Watson. 1988. Variable Trends in Economic Time Series. Journal of Economic Perspectives 2(3): 147-174.

Ozyildirim, Ataman and Victor Zarnowitz. 2006. Time Series Decomposition and Measurement of Business Cycles, Trends and Growth Cycles. Journal of Monetary Economics, 53(7), 1717-1739. 
${ }^{1}$ It has been argued that the US unemployment rate is stationary (see Mocan 1999 for a review), especially given that it is bounded by definition. This study simply relies on the particular unit root test as the basis for examining different de-trending techniques rather than joining the discussion of whether the (US) unemployment rate is stationary.

${ }^{2} \tau_{t}$ and $c_{t}$ represent permanent and cyclical component in both $\mathrm{BN}$ decomposition and HP filter.

3 Applying a more elaborated routine to determine the ARMA process for each unemployment series may not be practical (for example, Clements, Joutz, and Stekler 2007 discuss forecast evaluations).

4 The choice of smoothing parameter has little impact on empirical results. For example, when we set the smoothing parameter to 110,000 , a roughly 10 percent change from 129,600 (while still within reasonable set up according to Ravn and Uhlig 2002) the change in structural component is too small to be seen in Figure 1. The decomposition results are available from the authors upon request.

5 See Quercia, Riley, and $\mathrm{Ru}(2009)$ for a brief overview of the data.

6 This is done to control for possible endogenous mortgage interest rate on current mortgage.

7 "Distressed" prepayments are loans that are paid off early or refinanced because the borrower is under financial stress. For example, these prepayments could include a cash-out feature that is used for consumption or to pay off other outstanding debt obligations.

${ }^{8}$ Decomposition usually implies that the average of the structural components of 
unemployment rates are supposed to be very close to the average of the level while the average of the cyclical components tends to zero.

${ }^{9}$ Cyclical components of HP, BN and HPRS are not included in the figure because the relative change for Cyclical HP and Cyclical BN are very small. HPRS is not included because it is based on ranking and it is not appropriate to simulate one series without changing any other series. In addition, the "score" does not have continuous support. 10 The sensitivity measure is statistically insignificant in the level equation and we present it for reference purposes only.

11 Additional specifications used the expected change in cltv and the results are very similar (robust).

12 HPI series are either I(0) or I(1) for all cities and each forecasting rule is based on an ARMA process selected by information criteria. 


\section{Table 1: Augmented Dickey-Fuller Test for US Unemployment Rate and Its First Difference (1990-2009)}

Null Hypothesis: US unemployment rate has a unit root Exogenous: Constant

Lag Length: 3 (Automatic based on SIC, MAXLAG=14)

\begin{tabular}{|c|c|c|c|}
\hline & & $\mathrm{t}$-Statistic & Prob.* \\
\hline Augmented Dickey & $r$ test statistic & -0.528229 & 0.8820 \\
\hline Test critical values: & $\begin{array}{c}1 \% \text { level } \\
5 \% \text { level } \\
10 \% \text { level }\end{array}$ & $\begin{array}{l}-3.457984 \\
-2.873596 \\
-2.573270\end{array}$ & \\
\hline
\end{tabular}

*MacKinnon (1996) one-sided p-values.

Null Hypothesis: First difference of US unemployment rate has a unit root Exogenous: Constant

Lag Length: 2 (Automatic based on SIC, MAXLAG=14)

\begin{tabular}{lccc}
\hline \hline & & t-Statistic & Prob.* $^{*}$ \\
\hline \hline \multicolumn{2}{l}{ Augmented Dickey-Fuller test statistic } & -4.989747 & 0.0000 \\
\hline Test critical values: & 1\% level & -3.457984 & \\
& 5\% level & -2.873596 & \\
& 10\% level & -2.573270 & \\
\hline \hline
\end{tabular}

*MacKinnon (1996) one-sided p-values. 
Table 2: ARMA Processes Selected by Schwarz Information Criteria (BIC)

\begin{tabular}{lc}
\hline & $\begin{array}{c}\text { Number of county } \\
\text { unemployment rate series } \\
\text { selected by BIC }\end{array}$ \\
\hline ARMA process & 129 \\
ARMA $(1,0)$ & 58 \\
ARMA $(1,2)$ & 70 \\
ARMA(1,3) & 11 \\
ARMA $(1,4)$ & 5 \\
ARMA(2,0) & 23 \\
ARMA(2,1) & 26 \\
ARMA $(2,2)$ & 37 \\
ARMA $(2,3)$ & 31 \\
ARMA $(2,4)$ & 14 \\
ARMA $(3,0)$ & 9 \\
ARMA $(3,1)$ & 4 \\
ARMA $(3,2)$ & 24 \\
ARMA $(3,3)$ & 25 \\
ARMA $(3,4)$ & 17 \\
ARMA $(4,0)$ & 0 \\
ARMA $(4,1)$ & 0 \\
ARMA $(4,2)$ & 9 \\
ARMA $(4,3)$ & 18 \\
ARMA $(4,4)$ & 31 \\
\hline
\end{tabular}


Table 3: Number of Loans by Year Originated

\begin{tabular}{lc}
\hline Year & Number of loans \\
\hline 1991 & 2 \\
1992 & 18 \\
1993 & 266 \\
1994 & 380 \\
1995 & 584 \\
1996 & 674 \\
1997 & 1,363 \\
1998 & 1,817 \\
1999 & 1,737 \\
2000 & 3,137 \\
2001 & 3,475 \\
2002 & 2,570 \\
2003 & 1,682 \\
2004 & 1,688 \\
2005 & 1,624 \\
2006 & 1,152 \\
2007 & 369 \\
\hline Total & 22,538 \\
\hline
\end{tabular}


Table 4: Variable Definitions and Summary Statistics

\begin{tabular}{|c|c|c|c|c|c|}
\hline & Variable & Subcategory & Mean & Std dev & Note \\
\hline \multirow{4}{*}{ 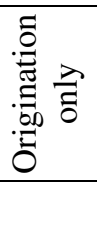 } & inc_ami & & 0.589 & 0.158 & Annual income divided by area medium income at loan origination. \\
\hline & $d t i$ & & 0.275 & 0.074 & $\begin{array}{l}\text { The fraction of combined income that goes toward mortgage payments or } \\
\text { front-end ratio. }\end{array}$ \\
\hline & fico & & 678 & 64 & Borrower's credit score at loan origination \\
\hline & Loans & & \multicolumn{2}{|c|}{22,538} & \\
\hline \multirow{17}{*}{ 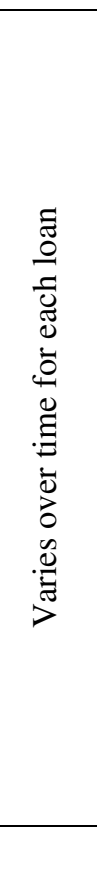 } & default & & 0.003 & 0.001 & The first 90-day delinquency on a mortgage. \\
\hline & prepayment & & 0.010 & 0.003 & A mortgage is paid off prematurely. \\
\hline & cltv & & 0.788 & 0.150 & Current loan amount divided by estimated house value. \\
\hline & cltv12 & & 0.760 & 0.140 & One year forecast of cltv. \\
\hline & refi & & 0.055 & 0.078 & $\begin{array}{l}\text { Percentage reduction in present value of future payments if refinance into } \\
\text { the market rate as a fraction. }\end{array}$ \\
\hline & refil2 & & 0.062 & 0.073 & One year forecast of refi \\
\hline & unempr & Observed & 5.430 & 1.814 & Observed county unemployment rate (percent). \\
\hline & & Cyclical HP & 0.001 & 0.994 & Cyclical component of "Observed" measured by HP filter. \\
\hline & & Cyclical BN & 0.006 & 0.864 & Cyclical component of "Observed" measured by BN decomposition. \\
\hline & & Structural HP & 5.429 & 1.530 & Permanent component of "Observed" measured by HP filter. \\
\hline & & Structural BN & 5.436 & 2.186 & Permanent component of "Observed" measured by BN decomposition. \\
\hline & & HPRS & 62147 & 29999 & Sum of county unemployment ranking by Structural HP. \\
\hline & varmrate & & $1.5 \mathrm{E}-05$ & $1.1 \mathrm{E}-05$ & 24-month forward-looking variance of national mortgage rate. \\
\hline & varhpi & & $2.2 \mathrm{E}-05$ & $4.1 \mathrm{E}-05$ & $\begin{array}{l}\text { 24-month forward-looking variance of quarterly percent change in the } \\
\text { MSA house price index by Federal Housing Finance Agency. }\end{array}$ \\
\hline & fdays & & 113 & 61 & Total days since foreclosure referral to sale, Cutts and Merrill (2008) \\
\hline & loan age & & 45 & 28 & Months \\
\hline & Observations & & & & \\
\hline
\end{tabular}

Note: * default and prepayment are the monthly hazard rates. HPRS sums unemployment rate (Structural HP) ranking of each month among all counties. The higher the individual ranking each month, the higher the Structural HP unemployment rate is that month. Different interest rates are tested for estimating refi and the results are robust to specifications. Missing values in variables lead to different sample sizes with different specifications. Sample size of the baseline specification is reported here and estimates for common variables are robust as shown later. 
Table 5: Default Baseline Results

\begin{tabular}{|c|c|c|c|c|c|c|c|c|c|c|c|c|}
\hline & & & \multicolumn{4}{|c|}{ Cyclical Components } & \multicolumn{6}{|c|}{ Permanent Components } \\
\hline & \multicolumn{2}{|c|}{ Observed } & \multicolumn{2}{|c|}{ HP } & \multicolumn{2}{|c|}{$\mathrm{BN}$} & \multicolumn{2}{|c|}{ HP } & \multicolumn{2}{|c|}{$\mathrm{BN}$} & \multicolumn{2}{|c|}{ HPRS } \\
\hline & Coef & Std Err & Coef & Std Err & Coef & Std Err & Coef & Std Err & Coef & Std Err & Coef & Std Err \\
\hline inc_ami & $-0.209 * * *$ & 0.023 & $-0.198 * * *$ & 0.023 & $-0.205^{* * *}$ & 0.023 & $-0.208 * * *$ & 0.023 & $-0.208 * * *$ & 0.024 & $-0.186 * * *$ & 0.023 \\
\hline$d t i$ & 0.024 & 0.023 & 0.023 & 0.022 & 0.025 & 0.023 & 0.030 & 0.024 & 0.028 & 0.023 & $0.040^{*}$ & 0.022 \\
\hline fico & $-0.784 * * *$ & 0.026 & $-0.751 * * *$ & 0.024 & $-0.778 * * *$ & 0.025 & $-0.823 * * *$ & 0.023 & $-0.789 * * *$ & 0.025 & $-0.735 * * *$ & 0.024 \\
\hline cltv & $0.561 * * *$ & 0.024 & $0.551 * * *$ & 0.020 & $0.505 * * *$ & 0.023 & $0.561 * * *$ & 0.023 & $0.497 * * *$ & 0.023 & $0.539 * * *$ & 0.021 \\
\hline unempr & $0.238 * * *$ & 0.019 & 0.024 & 0.021 & $0.048 * *$ & 0.019 & $0.331 * * *$ & 0.020 & $0.205 * * *$ & 0.018 & $0.144 * * *$ & 0.021 \\
\hline varmrate & 0.017 & 0.020 & $-0.049 * *$ & 0.022 & $-0.080 * * *$ & 0.020 & $-0.048 * *$ & 0.019 & -0.027 & 0.020 & $-0.060 * * *$ & 0.019 \\
\hline varhpi & $0.054 * * *$ & 0.019 & $0.104 * * *$ & 0.016 & $0.110 * * *$ & 0.017 & 0.010 & 0.020 & $0.075 * * *$ & 0.018 & $0.082 * * *$ & 0.017 \\
\hline locl & $-0.938 * * *$ & 0.096 & $-1.226 * * *$ & 0.293 & -0.094 & 0.093 & $-1.349 * * *$ & 0.101 & $-0.818 * * *$ & 0.092 & $-0.528 * * *$ & 0.103 \\
\hline $\operatorname{loc} 2$ & $-3.366 * * *$ & 0.697 & 0.065 & 0.104 & $-2.116 * * *$ & 0.587 & $-5.102 * * *$ & 0.895 & $-3.495 * * *$ & 0.810 & $-1.766^{* * *}$ & 0.297 \\
\hline$q 1$ & 0 & & 0 & & 0 & & 0 & & 0 & & 0 & \\
\hline$q 2$ & -0.156 & 0.133 & -0.169 & 0.158 & $-0.319 * *$ & 0.136 & $-0.225 * *$ & 0.105 & $-0.377 * * *$ & 0.120 & 0.041 & 0.136 \\
\hline Loans & \multicolumn{2}{|c|}{22,538} & \multicolumn{2}{|c|}{22,538} & \multicolumn{2}{|c|}{20,322} & \multicolumn{2}{|c|}{22,538} & \multicolumn{2}{|c|}{20,322} & \multicolumn{2}{|c|}{22,538} \\
\hline Obs & \multicolumn{2}{|c|}{968,561} & \multicolumn{2}{|c|}{968,561} & \multicolumn{2}{|c|}{895,274} & \multicolumn{2}{|c|}{968,561} & \multicolumn{2}{|c|}{895,274} & \multicolumn{2}{|c|}{968,561} \\
\hline Loglike & \multicolumn{2}{|c|}{$-79,337$} & \multicolumn{2}{|c|}{$-79,462$} & \multicolumn{2}{|c|}{$-71,731$} & \multicolumn{2}{|c|}{$-79,148$} & \multicolumn{2}{|c|}{$-71,619$} & \multicolumn{2}{|c|}{$-79,459$} \\
\hline
\end{tabular}

Note: * indicates significance at 90 percent, ** indicates significance at 95 percent, and $* * *$ indicates significance at 99 percent. $l o c l$ and $l o c 2$ are shift parameters of the two heterogeneity groups. $q 1$ and $q 2$ are logistic transformation parameters for the heterogeneity mass points. $q 1$ is normalized to zero. All unemployment variables are scaled to mean 4.5 and standard deviation 1 for identification. All other variables (other than the interaction terms) are scaled to mean 0 and standard deviation 1. unempr is the observed county unemployment rate, its HP cyclical component, its BN cyclical component, its HP permanent component, its BN permanent component, and its HP Ranking Score. These specifications are jointly estimated with Table 6. 
Table 6: Prepayment Baseline Results

\begin{tabular}{|c|c|c|c|c|c|c|c|c|c|c|c|c|}
\hline & & & \multicolumn{4}{|c|}{ Cyclical Components } & \multicolumn{6}{|c|}{ Permanent Components } \\
\hline & \multicolumn{2}{|c|}{ Observed } & \multicolumn{2}{|c|}{ HP } & \multicolumn{2}{|c|}{$\mathrm{BN}$} & \multicolumn{2}{|c|}{ HP } & \multicolumn{2}{|c|}{$\mathrm{BN}$} & \multicolumn{2}{|c|}{ HPRS } \\
\hline & Coef & Std Err & Coef & Std Err & Coef & Std Err & Coef & Std Err & Coef & Std Err & Coef & Std Err \\
\hline inc_ami & $0.356 * * *$ & 0.013 & $0.351 * * *$ & 0.013 & $0.341 * * *$ & 0.015 & $0.339 * * *$ & 0.013 & $0.338 * * *$ & 0.015 & $0.359 * * *$ & 0.014 \\
\hline$d t i$ & $0.225 * * *$ & 0.013 & $0.225 * * *$ & 0.013 & $0.188 * * *$ & 0.014 & $0.213 * * *$ & 0.012 & $0.184 * * *$ & 0.014 & $0.229 * * *$ & 0.013 \\
\hline fico & $0.255^{* * *}$ & 0.013 & $0.237 * * *$ & 0.013 & $0.288 * * *$ & 0.014 & $0.244 * * *$ & 0.012 & $0.291 * * *$ & 0.014 & $0.239 * * *$ & 0.014 \\
\hline cltv & $-0.226 * * *$ & 0.014 & $-0.271 * * *$ & 0.014 & $-0.184 * * *$ & 0.015 & $-0.202 * * *$ & 0.013 & $-0.158 * * *$ & 0.015 & $-0.267 * * *$ & 0.014 \\
\hline refi & $0.426 * * *$ & 0.014 & $0.334 * * *$ & 0.015 & $0.386 * * *$ & 0.015 & $0.389 * * *$ & 0.013 & $0.418 * * *$ & 0.015 & $0.382 * * *$ & 0.013 \\
\hline unempr & $-0.149 * * *$ & 0.012 & $0.088 * * *$ & 0.012 & $-0.079 * * *$ & 0.011 & $-0.278 * * *$ & 0.012 & $-0.152 * * *$ & 0.012 & $-0.046 * * *$ & 0.013 \\
\hline varmrate & $-0.208 * * *$ & 0.012 & $-0.149 * * *$ & 0.012 & $-0.144 * * *$ & 0.012 & $-0.195 * * *$ & 0.012 & $-0.175^{* * *}$ & 0.012 & $-0.176 * * *$ & 0.011 \\
\hline varhpi & 0.016 & 0.011 & -0.002 & 0.011 & $-0.027 * *$ & 0.012 & $0.059 * * *$ & 0.011 & -0.002 & 0.012 & 0.000 & 0.011 \\
\hline locl & $-0.205^{* *}$ & 0.099 & $0.312 * * *$ & 0.086 & $-0.482 * * *$ & 0.092 & $0.518 * * *$ & 0.081 & -0.101 & 0.086 & $-0.806^{* * *}$ & 0.114 \\
\hline $\operatorname{loc} 2$ & $1.499 * * *$ & 0.079 & $-1.444 * * *$ & 0.123 & $1.321 * * *$ & 0.082 & $1.992 * * *$ & 0.068 & $1.645 * * *$ & 0.079 & $0.999 * * *$ & 0.084 \\
\hline$q 1$ & 0 & & 0 & & 0 & & 0 & & 0 & & 0 & \\
\hline$q 2$ & -0.156 & 0.133 & -0.169 & 0.158 & $-0.319 * *$ & 0.136 & $-0.225 * *$ & 0.105 & $-0.377 * * *$ & 0.120 & 0.041 & 0.136 \\
\hline Obs & \multicolumn{2}{|c|}{968,561} & \multicolumn{2}{|c|}{968,561} & \multicolumn{2}{|c|}{895,274} & \multicolumn{2}{|c|}{968,561} & \multicolumn{2}{|c|}{895,274} & \multicolumn{2}{|c|}{968,561} \\
\hline Loglike & \multicolumn{2}{|c|}{$-79,337$} & \multicolumn{2}{|c|}{$-79,462$} & \multicolumn{2}{|c|}{$-71,731$} & \multicolumn{2}{|c|}{$-79,148$} & \multicolumn{2}{|c|}{$-71,619$} & \multicolumn{2}{|c|}{$-79,459$} \\
\hline
\end{tabular}

Note: * indicates significance at 90 percent, ** indicates significance at 95 percent, and *** indicates significance at 99 percent. locl and loc 2 are shift parameters of the two heterogeneity groups. $q 1$ and $q 2$ are logistic transformation parameters for the heterogeneity mass points. $q 1$ is normalized to zero. All unemployment variables are scaled to mean 4.5 and standard deviation 1 for identification. All other variables (other than the interaction terms) are scaled to mean 0 and standard deviation 1. unempr is the observed county unemployment rate, its HP cyclical component, its BN cyclical component, its HP permanent component, its BN permanent component, and its HP Ranking Score. These specifications are jointly estimated with Table 5. 
Table 7: Default Sensitivity Results

\begin{tabular}{|c|c|c|c|c|c|c|c|c|c|c|c|c|}
\hline & & & \multicolumn{4}{|c|}{ Cyclical Components } & \multicolumn{6}{|c|}{ Permanent Components } \\
\hline & \multicolumn{2}{|c|}{ Observed } & \multicolumn{2}{|c|}{ HP } & \multicolumn{2}{|c|}{$\mathrm{BN}$} & \multicolumn{2}{|c|}{ HP } & \multicolumn{2}{|c|}{$\mathrm{BN}$} & \multicolumn{2}{|c|}{ HPRS } \\
\hline & Coef & Std Err & Coef & Std Err & Coef & Std Err & Coef & Std Err & Coef & Std Err & Coef & Std Err \\
\hline inc_ami & $-0.355 * * *$ & 0.089 & $-0.266^{* * *}$ & 0.094 & $-0.379 * * *$ & 0.095 & $-0.355 * * *$ & 0.097 & $-0.365 * * *$ & 0.093 & -0.144 & 0.112 \\
\hline$d t i$ & -0.096 & 0.090 & -0.014 & 0.091 & -0.112 & 0.092 & -0.163 & 0.101 & -0.112 & 0.093 & 0.124 & 0.111 \\
\hline fico & $-1.066^{* * *}$ & 0.088 & $-1.039 * * *$ & 0.087 & $-0.877 * * *$ & 0.084 & $-0.815 * * *$ & 0.102 & $-1.023 * * *$ & 0.091 & $-0.960 * * *$ & 0.098 \\
\hline cltv & $0.505 * * *$ & 0.085 & $0.832 * * *$ & 0.087 & $0.623 * * *$ & 0.079 & $0.357 * * *$ & 0.094 & $0.386 * * *$ & 0.095 & $0.276^{* *}$ & 0.112 \\
\hline unempr & $0.300 * * *$ & 0.023 & $0.076 * * *$ & 0.026 & $0.055^{* *}$ & 0.023 & $0.324 * * *$ & 0.024 & $0.253 * * *$ & 0.024 & $0.168 * * *$ & 0.026 \\
\hline varmrate & $-0.211 * *$ & 0.084 & $0.402 * * *$ & 0.082 & 0.101 & 0.092 & $-0.164 * *$ & 0.081 & $-0.193 * *$ & 0.090 & $-0.418 * * *$ & 0.096 \\
\hline varhpi & 0.086 & 0.059 & -0.015 & 0.049 & 0.036 & 0.066 & 0.062 & 0.083 & 0.105 & 0.070 & $0.391 * * *$ & 0.095 \\
\hline unempr_inc_ami & $0.031 *$ & 0.017 & 0.014 & 0.020 & $0.038^{*}$ & 0.020 & 0.030 & 0.019 & $0.032 *$ & 0.019 & -0.009 & 0.023 \\
\hline unempr_dti & 0.025 & 0.017 & 0.007 & 0.019 & 0.030 & 0.019 & $0.039 *$ & 0.020 & 0.028 & 0.018 & -0.018 & 0.023 \\
\hline unempr_fico & $0.063 * * *$ & 0.019 & $0.063 * * *$ & 0.018 & 0.022 & 0.018 & -0.001 & 0.021 & $0.048 * *$ & 0.019 & $0.051 * *$ & 0.020 \\
\hline unempr_cltv & 0.006 & 0.016 & $-0.059 * * *$ & 0.018 & -0.026 & 0.016 & $0.040 * *$ & 0.018 & 0.022 & 0.020 & $0.061 * * *$ & 0.023 \\
\hline unempr_varmrate & $0.049 * * *$ & 0.017 & $-0.107 * * *$ & 0.019 & $-0.039 * *$ & 0.019 & 0.023 & 0.015 & $0.036^{*}$ & 0.019 & $0.074 * * *$ & 0.020 \\
\hline unempr_varhpi & -0.007 & 0.009 & $0.021 * *$ & 0.009 & 0.016 & 0.014 & -0.009 & 0.013 & -0.005 & 0.012 & $-0.064 * * *$ & 0.020 \\
\hline locl & $-1.208 * * *$ & 0.117 & $-0.251 * *$ & 0.127 & $-2.010 * * *$ & 0.536 & $-1.333 * * *$ & 0.118 & $-1.040 * * *$ & 0.117 & $-1.645^{* * *}$ & 0.211 \\
\hline loc 2 & $-2.868 * * *$ & 0.458 & $-1.475 * * *$ & 0.289 & -0.120 & 0.113 & $-5.373 * * *$ & 0.963 & $-3.988 * * *$ & 1.351 & $-0.668 * * *$ & 0.130 \\
\hline$q 1$ & 0 & & 0 & & 0 & & 0 & & 0 & & 0 & \\
\hline$q 2$ & 0.038 & 0.171 & 0.148 & 0.168 & $0.280^{*}$ & 0.151 & $-0.276 * * *$ & 0.101 & $-0.413 * * *$ & 0.155 & -0.133 & 0.130 \\
\hline Loans & \multicolumn{2}{|c|}{22,538} & \multicolumn{2}{|c|}{22,538} & \multicolumn{2}{|c|}{20,322} & \multicolumn{2}{|c|}{22,538} & \multicolumn{2}{|c|}{20,322} & \multicolumn{2}{|c|}{22,538} \\
\hline Obs & \multicolumn{2}{|c|}{968,561} & \multicolumn{2}{|c|}{968,561} & \multicolumn{2}{|c|}{895,274} & \multicolumn{2}{|c|}{968,561} & \multicolumn{2}{|c|}{895,274} & \multicolumn{2}{|c|}{968,561} \\
\hline Loglike & \multicolumn{2}{|c|}{$-79,257$} & \multicolumn{2}{|c|}{$-79,401$} & \multicolumn{2}{|c|}{$-71,699$} & \multicolumn{2}{|c|}{$-79,071$} & \multicolumn{2}{|c|}{$-71,548$} & \multicolumn{2}{|c|}{$-79,439$} \\
\hline
\end{tabular}

Note: * indicates significance at 90 percent, ** indicates significance at 95 percent, and *** indicates significance at 99 percent. loc 1 and $l o c 2$ are shift parameters of the two heterogeneity groups. $q 1$ and $q 2$ are logistic transformation parameters for the heterogeneity mass points. $q 1$ is normalized to zero. All unemployment variables are scaled to mean 4.5 and standard deviation 1 for identification. All other variables (other than the interaction terms) are scaled to mean 0 and standard deviation 1. unempr is the observed county unemployment rate, its HP cyclical component, its BN cyclical component, its HP permanent component, its BN permanent component, and its HP Ranking Score. These specifications are jointly estimated with Table 8 . 
Table 8: Prepayment Sensitivity Results

\begin{tabular}{|c|c|c|c|c|c|c|c|c|c|c|c|c|}
\hline & & & \multicolumn{4}{|c|}{ Cyclical Components } & \multicolumn{6}{|c|}{ Permanent Components } \\
\hline & \multicolumn{2}{|c|}{ Observed } & \multicolumn{2}{|c|}{ HP } & \multicolumn{2}{|c|}{$\mathrm{BN}$} & \multicolumn{2}{|c|}{ HP } & \multicolumn{2}{|c|}{$\mathrm{BN}$} & \multicolumn{2}{|c|}{ HPRS } \\
\hline & Coef & Std Err & Coef & Std Err & Coef & Std Err & Coef & Std Err & Coef & Std Err & Coef & Std Err \\
\hline inc_ami & $0.172 * * *$ & 0.056 & $0.140 * * *$ & 0.054 & $0.367 * * *$ & 0.053 & $0.270 * * *$ & 0.059 & $0.178 * * *$ & 0.058 & $0.288 * * *$ & 0.063 \\
\hline$d t i$ & $0.165 * * *$ & 0.056 & 0.030 & 0.055 & $0.230 * * *$ & 0.050 & $0.285^{* * *}$ & 0.061 & $0.105^{*}$ & 0.058 & 0.063 & 0.062 \\
\hline fico & 0.017 & 0.052 & 0.013 & 0.050 & $0.277 * * *$ & 0.048 & $0.141 * * *$ & 0.055 & $0.098^{*}$ & 0.053 & $0.268 * * *$ & 0.058 \\
\hline cltv & $0.117 * *$ & 0.050 & $-0.153 * * *$ & 0.048 & $-0.099 * *$ & 0.046 & $0.164 * * *$ & 0.053 & $0.093 *$ & 0.050 & $-0.206 * * *$ & 0.060 \\
\hline refi & $0.543 * * *$ & 0.061 & $0.368 * * *$ & 0.060 & $0.343 * * *$ & 0.057 & $0.651 * * *$ & 0.063 & $0.446 * * *$ & 0.063 & $0.665 * * *$ & 0.060 \\
\hline unempr & $-0.128 * * *$ & 0.014 & $0.078 * * *$ & 0.013 & $-0.077 * * *$ & 0.013 & $-0.245^{* * *}$ & 0.014 & $-0.139 * * *$ & 0.014 & $-0.047 * * *$ & 0.013 \\
\hline varmrate & $-0.427 * * *$ & 0.055 & $-0.296 * * *$ & 0.049 & $-0.430 * * *$ & 0.056 & $-0.388 * * *$ & 0.055 & $-0.491 * * *$ & 0.058 & 0.044 & 0.053 \\
\hline varhpi & $0.302 * * *$ & 0.046 & 0.042 & 0.035 & $0.201 * * *$ & 0.059 & $0.444 * * *$ & 0.050 & $0.339 * * *$ & 0.051 & 0.018 & 0.058 \\
\hline unempr_inc_ami & $0.039 * * *$ & 0.012 & $0.043 * * *$ & 0.011 & -0.007 & 0.011 & 0.015 & 0.013 & $0.034 * * *$ & 0.012 & 0.014 & 0.013 \\
\hline unempr_dti & 0.013 & 0.012 & $0.040 * * *$ & 0.011 & -0.010 & 0.011 & -0.017 & 0.013 & 0.017 & 0.012 & $0.035 * * *$ & 0.013 \\
\hline unempr_fico & $0.050 * * *$ & 0.011 & $0.046 * * *$ & 0.010 & 0.002 & 0.010 & $0.022 *$ & 0.012 & $0.042 * * *$ & 0.011 & -0.008 & 0.013 \\
\hline unempr_cltv & $-0.072 * * *$ & 0.010 & $-0.023 * *$ & 0.010 & -0.016 & 0.010 & $-0.078 * * *$ & 0.011 & $-0.050 * * *$ & 0.010 & -0.011 & 0.012 \\
\hline unempr_refi & $-0.028 * *$ & 0.014 & -0.007 & 0.013 & 0.009 & 0.013 & $-0.060 * * *$ & 0.014 & -0.007 & 0.014 & $-0.063 * * *$ & 0.013 \\
\hline unempr_varmrate & $0.051 * * *$ & 0.012 & $0.033 * * *$ & 0.011 & $0.061 * * *$ & 0.012 & $0.045^{* * *}$ & 0.012 & $0.071 * * *$ & 0.013 & $-0.050 * * *$ & 0.012 \\
\hline unempr_varhpi & $-0.059 * * *$ & 0.010 & -0.008 & 0.007 & $-0.052 * * *$ & 0.014 & $-0.080 * * *$ & 0.010 & $-0.071 * * *$ & 0.011 & -0.004 & 0.012 \\
\hline locl & $-0.352 * * *$ & 0.128 & $-1.324 * * *$ & 0.127 & $1.259 * * *$ & 0.091 & $0.433 * * *$ & 0.081 & -0.087 & 0.101 & $0.965 * * *$ & 0.080 \\
\hline $\operatorname{loc} 2$ & $1.354 * * *$ & 0.092 & $0.371 * * *$ & 0.092 & $-0.490 * * *$ & 0.103 & $1.880 * * *$ & 0.070 & $1.599 * * *$ & 0.096 & $-0.840 * * *$ & 0.112 \\
\hline$q 1$ & 0 & & 0 & & 0 & & 0 & & 0 & & 0 & \\
\hline$q 2$ & 0.038 & 0.171 & 0.148 & 0.168 & $0.280^{*}$ & 0.151 & $-0.276 * * *$ & 0.101 & $-0.413 * * *$ & 0.155 & -0.133 & 0.130 \\
\hline Loans & \multicolumn{2}{|c|}{22,538} & \multicolumn{2}{|c|}{22,538} & \multicolumn{2}{|c|}{20,322} & \multicolumn{2}{|c|}{22,538} & \multicolumn{2}{|c|}{20,322} & \multicolumn{2}{|c|}{22,538} \\
\hline Obs & \multicolumn{2}{|c|}{968,561} & \multicolumn{2}{|c|}{968,561} & \multicolumn{2}{|c|}{895,274} & \multicolumn{2}{|c|}{968,561} & \multicolumn{2}{|c|}{895,274} & \multicolumn{2}{|c|}{968,561} \\
\hline Loglike & \multicolumn{2}{|c|}{$-79,257$} & \multicolumn{2}{|c|}{$-79,401$} & \multicolumn{2}{|c|}{$-71,699$} & \multicolumn{2}{|c|}{$-79,071$} & \multicolumn{2}{|c|}{$-71,548$} & \multicolumn{2}{|c|}{$-79,439$} \\
\hline
\end{tabular}

Note: * indicates significance at 90 percent, ** indicates significance at 95 percent, and *** indicates significance at 99 percent. locl and loc 2 are shift parameters of the two heterogeneity groups. $q 1$ and $q 2$ are logistic transformation parameters for the heterogeneity mass points. $q 1$ is normalized to zero. All unemployment variables are scaled to mean 4.5 and standard deviation 1 for identification. All other variables (other than the interaction terms) are scaled to mean 0 and standard deviation 1. unempr is the observed county unemployment rate, its HP cyclical component, its BN cyclical component, its HP permanent component, its BN permanent component, and its HP Ranking Score. These specifications are jointly estimated with Table 7. 
Table 9: Default Results with Expectations

\begin{tabular}{|c|c|c|c|c|c|c|c|c|c|c|c|c|}
\hline & & & \multicolumn{4}{|c|}{ Cyclical Components } & \multicolumn{6}{|c|}{ Permanent Components } \\
\hline & \multicolumn{2}{|c|}{ Observed } & \multicolumn{2}{|c|}{ HP } & \multicolumn{2}{|c|}{$\mathrm{BN}$} & \multicolumn{2}{|c|}{$\mathrm{HP}$} & \multicolumn{2}{|c|}{$\mathrm{BN}$} & \multicolumn{2}{|c|}{ HPRS } \\
\hline & Coef & Std Err & Coef & Std Err & Coef & Std Err & Coef & Std Err & Coef & Std Err & Coef & Std Err \\
\hline inc_ami & $-0.201 * * *$ & 0.024 & $-0.198 * * *$ & 0.023 & $-0.207 * * *$ & 0.024 & $-0.203 * * *$ & 0.024 & $-0.209 * * *$ & 0.024 & $-0.188 * * *$ & 0.023 \\
\hline$d t i$ & $0.043 *$ & 0.023 & 0.035 & 0.022 & 0.030 & 0.023 & $0.045^{*}$ & 0.023 & 0.034 & 0.023 & $0.052 * *$ & 0.022 \\
\hline fico & $-0.802 * * *$ & 0.027 & $-0.769 * * *$ & 0.024 & $-0.776 * * *$ & 0.026 & $-0.842 * * *$ & 0.025 & $-0.795 * * *$ & 0.028 & $-0.757 * * *$ & 0.025 \\
\hline cltv & $0.496 * * *$ & 0.033 & $0.441 * * *$ & 0.035 & $0.445 * * *$ & 0.035 & $0.514 * * *$ & 0.037 & $0.480 * * *$ & 0.034 & $0.435 * * *$ & 0.035 \\
\hline cltv12 & 0.014 & 0.034 & $0.092 * * *$ & 0.035 & $0.088 * *$ & 0.035 & -0.005 & 0.038 & 0.030 & 0.034 & $0.086^{* *}$ & 0.035 \\
\hline unempr & $0.238 * * *$ & 0.020 & 0.019 & 0.022 & $0.038 * *$ & 0.019 & $0.339 * * *$ & 0.022 & $0.195 * * *$ & 0.018 & $0.163 * * *$ & 0.021 \\
\hline varmrate & 0.019 & 0.020 & $-0.054 * *$ & 0.022 & $-0.067 * * *$ & 0.020 & $-0.045 * *$ & 0.019 & -0.016 & 0.020 & $-0.064 * * *$ & 0.019 \\
\hline varhpi & $0.053 * * *$ & 0.018 & $0.098 * * *$ & 0.015 & $0.103 * * *$ & 0.016 & 0.005 & 0.019 & $0.074 * * *$ & 0.018 & $0.077 * * *$ & 0.016 \\
\hline fdays & 0.010 & 0.021 & 0.026 & 0.021 & 0.022 & 0.021 & -0.027 & 0.022 & 0.011 & 0.022 & 0.006 & 0.020 \\
\hline locl & $-0.819 * * *$ & 0.100 & $0.199 *$ & 0.108 & 0.080 & 0.095 & $-1.260 * * *$ & 0.115 & $-0.636 * * *$ & 0.096 & $-0.503 * * *$ & 0.105 \\
\hline loc2 & $-2.816^{* * *}$ & 0.406 & $-1.067 * * *$ & 0.217 & $-1.387 * * *$ & 0.281 & $-4.018 * * *$ & 0.522 & $-2.581 * * *$ & 0.435 & $-1.826 * * *$ & 0.243 \\
\hline$q 1$ & 0 & & 0 & & 0 & & 0 & & 0 & & 0 & \\
\hline$q 2$ & 0.147 & 0.135 & $0.480 * * *$ & 0.151 & 0.187 & 0.141 & 0.052 & 0.144 & 0.050 & 0.142 & $0.289 * *$ & 0.134 \\
\hline Loans & \multicolumn{2}{|c|}{21,315} & \multicolumn{2}{|c|}{21,315} & \multicolumn{2}{|c|}{21,315} & \multicolumn{2}{|c|}{21,315} & \multicolumn{2}{|c|}{21,315} & \multicolumn{2}{|c|}{21,315} \\
\hline Obs & \multicolumn{2}{|c|}{936,828} & \multicolumn{2}{|c|}{936,828} & \multicolumn{2}{|c|}{895,274} & \multicolumn{2}{|c|}{936,828} & \multicolumn{2}{|c|}{895,274} & \multicolumn{2}{|c|}{936,828} \\
\hline Loglike & \multicolumn{2}{|c|}{$-74,702$} & \multicolumn{2}{|c|}{$-74,850$} & \multicolumn{2}{|c|}{$-71,380$} & \multicolumn{2}{|c|}{$-74,545$} & \multicolumn{2}{|c|}{$-71,271$} & \multicolumn{2}{|c|}{$-74,795$} \\
\hline
\end{tabular}

Note: * indicates significance at 90 percent, ** indicates significance at 95 percent, and $* * *$ indicates significance at 99 percent. loc 1 and $l o c 2$ are shift parameters of the two heterogeneity groups. $q 1$ and $q 2$ are logistic transformation parameters for the heterogeneity mass points. $q 1$ is normalized to zero. All unemployment variables are scaled to mean 4.5 and standard deviation 1 for identification. All other variables (other than the interaction terms) are scaled to mean 0 and standard deviation 1. unempr is the observed county unemployment rate, its HP cyclical component, its BN cyclical component, its HP permanent component, its BN permanent component, and its HP Ranking Score. These specifications are jointly estimated with Table 10. 
Table 10: Prepayment Results with Expectations

\begin{tabular}{|c|c|c|c|c|c|c|c|c|c|c|c|c|}
\hline & & & \multicolumn{4}{|c|}{ Cyclical Components } & \multicolumn{6}{|c|}{ Permanent Components } \\
\hline & \multicolumn{2}{|c|}{ Observed } & \multicolumn{2}{|c|}{ HP } & \multicolumn{2}{|c|}{$\mathrm{BN}$} & \multicolumn{2}{|c|}{ HP } & \multicolumn{2}{|c|}{$\mathrm{BN}$} & \multicolumn{2}{|c|}{ HPRS } \\
\hline & Coef & Std Err & Coef & Std Err & Coef & Std Err & Coef & Std Err & Coef & Std Err & Coef & Std Err \\
\hline inc_ami & $0.349 * * *$ & 0.014 & $0.340 * * *$ & 0.014 & $0.347 * * *$ & 0.014 & $0.336 * * *$ & 0.014 & $0.349 * * *$ & 0.014 & $0.350 * * *$ & 0.014 \\
\hline$d t i$ & $0.180^{* * *}$ & 0.014 & $0.184 * * *$ & 0.014 & $0.184 * * *$ & 0.014 & $0.171 * * *$ & 0.013 & $0.181 * * *$ & 0.014 & $0.180 * * *$ & 0.014 \\
\hline fico & $0.287 * * *$ & 0.013 & $0.273 * * *$ & 0.013 & $0.283 * * *$ & 0.014 & $0.275 * * *$ & 0.012 & $0.287 * * *$ & 0.014 & $0.271 * * *$ & 0.014 \\
\hline cltv & $-0.128 * * *$ & 0.035 & -0.053 & 0.034 & $-0.123 * * *$ & 0.036 & $-0.148 * * *$ & 0.034 & $-0.160 * * *$ & 0.036 & $-0.079 * *$ & 0.035 \\
\hline cltv12 & $-0.117 * * *$ & 0.034 & $-0.221 * * *$ & 0.032 & $-0.152 * * *$ & 0.034 & $-0.081 * *$ & 0.033 & $-0.094 * * *$ & 0.035 & $-0.198 * * *$ & 0.033 \\
\hline refi & $0.491 * * *$ & 0.051 & $0.544 * * *$ & 0.051 & $0.546 * * *$ & 0.053 & $0.470 * * *$ & 0.051 & $0.512 * * *$ & 0.053 & $0.534 * * *$ & 0.051 \\
\hline refil2 & 0.044 & 0.051 & $-0.085^{*}$ & 0.051 & -0.054 & 0.052 & 0.020 & 0.050 & 0.013 & 0.052 & -0.040 & 0.051 \\
\hline unempr & $-0.172 * * *$ & 0.013 & $0.061 * * *$ & 0.013 & $-0.066 * * *$ & 0.011 & $-0.281 * * *$ & 0.013 & $-0.153 * * *$ & 0.012 & $-0.121 * * *$ & 0.013 \\
\hline varmrate & $-0.116^{* * *}$ & 0.013 & $-0.054 * * *$ & 0.013 & $-0.064 * * *$ & 0.013 & $-0.099 * * *$ & 0.013 & $-0.096^{* * *}$ & 0.013 & $-0.073 * * *$ & 0.013 \\
\hline varhpi & 0.003 & 0.012 & -0.017 & 0.012 & $-0.031 * *$ & 0.012 & $0.044 * * *$ & 0.012 & -0.010 & 0.012 & -0.003 & 0.012 \\
\hline fdays & $0.138 * * *$ & 0.014 & $0.118 * * *$ & 0.014 & $0.125 * * *$ & 0.014 & $0.154 * * *$ & 0.014 & $0.140 * * *$ & 0.014 & $0.142 * * *$ & 0.014 \\
\hline locl & $-0.343^{* * *}$ & 0.117 & $-1.625 * * *$ & 0.151 & $-0.884 * * *$ & 0.118 & $0.333 * * *$ & 0.110 & $-0.383^{* * *}$ & 0.113 & $-0.692 * * *$ & 0.126 \\
\hline loc2 & $1.413 * * *$ & 0.079 & $0.264 * * *$ & 0.084 & $0.937 * * *$ & 0.074 & $1.849 * * *$ & 0.076 & $1.357 * * *$ & 0.080 & $1.153 * * *$ & 0.079 \\
\hline$q 1$ & 0 & & 0 & & 0 & & 0 & & 0 & & 0 & \\
\hline$q 2$ & 0.147 & 0.135 & $0.480 * * *$ & 0.151 & 0.187 & 0.141 & 0.052 & 0.144 & 0.050 & 0.142 & $0.289 * *$ & 0.134 \\
\hline Loans & \multicolumn{2}{|c|}{21,315} & \multicolumn{2}{|c|}{21,315} & \multicolumn{2}{|c|}{21,315} & \multicolumn{2}{|c|}{21,315} & \multicolumn{2}{|c|}{21,315} & \multicolumn{2}{|c|}{21,315} \\
\hline Obs & \multicolumn{2}{|c|}{936,828} & \multicolumn{2}{|c|}{936,828} & \multicolumn{2}{|c|}{895,274} & \multicolumn{2}{|c|}{936,828} & \multicolumn{2}{|c|}{895,274} & \multicolumn{2}{|c|}{936,828} \\
\hline Loglike & \multicolumn{2}{|c|}{$-74,702$} & \multicolumn{2}{|c|}{$-74,850$} & \multicolumn{2}{|c|}{$-71,380$} & \multicolumn{2}{|c|}{$-74,545$} & \multicolumn{2}{|c|}{$-71,271$} & \multicolumn{2}{|c|}{$-74,795$} \\
\hline
\end{tabular}

Note: * indicates significance at 90 percent, ** indicates significance at 95 percent, and *** indicates significance at 99 percent. $l o c 1$ and $l o c 2$ are shift parameters of the two heterogeneity groups. $q 1$ and $q 2$ are logistic transformation parameters for the heterogeneity mass points. $q 1$ is normalized to zero. All unemployment variables are scaled to mean 4.5 and standard deviation 1 for identification. All other variables (other than the interaction terms) are scaled to mean 0 and standard deviation 1. unempr is the observed of county unemployment rate, its HP cyclical component, its BN cyclical component, its HP permanent component, its BN permanent component, and its HP Ranking Score. These specifications are jointly estimated with Table 9. 
Table 11: 30-Days Delinquency Results with Expectations

\begin{tabular}{|c|c|c|c|c|c|c|c|c|c|c|c|c|}
\hline & & & \multicolumn{4}{|c|}{ Cyclical Components } & \multicolumn{6}{|c|}{ Permanent Components } \\
\hline & \multicolumn{2}{|c|}{ Observed } & \multicolumn{2}{|c|}{ HP } & \multicolumn{2}{|c|}{$\mathrm{BN}$} & \multicolumn{2}{|c|}{ HP } & \multicolumn{2}{|c|}{$\mathrm{BN}$} & \multicolumn{2}{|c|}{ HPRS } \\
\hline & Coef & Std Err & Coef & Std Err & Coef & Std Err & Coef & Std Err & Coef & Std Err & Coef & Std Err \\
\hline inc_ami & $-0.102 * * *$ & 0.022 & $-0.178 * * *$ & 0.022 & $-0.133 * * *$ & 0.021 & $-0.099 * * *$ & 0.025 & $-0.119 * * *$ & 0.022 & $-0.166 * * *$ & 0.022 \\
\hline$d t i$ & $0.118 * * *$ & 0.022 & $0.055^{* *}$ & 0.021 & $0.060 * * *$ & 0.020 & $0.143 * * *$ & 0.026 & $0.091 * * *$ & 0.021 & $0.070 * * *$ & 0.021 \\
\hline fico & $-0.793 * * *$ & 0.022 & $-0.842 * * *$ & 0.028 & $-0.708 * * *$ & 0.019 & $-0.911 * * *$ & 0.025 & $-0.776 * * *$ & 0.023 & $-0.807 * * *$ & 0.032 \\
\hline cltv & $0.173 * * *$ & 0.047 & $0.203 * * *$ & 0.046 & $0.119 * *$ & 0.048 & 0.055 & 0.049 & $0.175 * * *$ & 0.048 & $0.170 * * *$ & 0.045 \\
\hline cltv 12 & -0.049 & 0.040 & $0.157 * * *$ & 0.040 & $0.146^{* * * *}$ & 0.039 & 0.004 & 0.042 & -0.018 & 0.042 & $0.206 * * *$ & 0.039 \\
\hline unempr & $0.538 * * *$ & 0.017 & $0.194 * * *$ & 0.019 & $0.189 * * *$ & 0.012 & $0.763 * * *$ & 0.025 & $0.461 * * *$ & 0.015 & $0.158 * * *$ & 0.020 \\
\hline varmrate & $0.063 * * *$ & 0.019 & $-0.041 * *$ & 0.020 & $-0.151 * * *$ & 0.018 & $-0.096 * * *$ & 0.018 & -0.009 & 0.019 & $-0.136 * * *$ & 0.018 \\
\hline varhpi & 0.022 & 0.015 & $0.147 * * *$ & 0.013 & $0.121 * * *$ & 0.012 & $-0.070 * * *$ & 0.019 & $0.066^{* * *}$ & 0.014 & $0.116 * * *$ & 0.014 \\
\hline fdays & $0.066^{* * * *}$ & 0.020 & $0.123 * * *$ & 0.021 & $0.094 * * *$ & 0.019 & 0.019 & 0.022 & $0.077 * * *$ & 0.020 & $0.078 * * *$ & 0.020 \\
\hline locl 1 & $-6.772 * * *$ & 0.337 & $-2.357 * * *$ & 0.103 & $-3.296 * * *$ & 0.170 & $-4.969 * * *$ & 0.109 & $-6.064 * * *$ & 0.368 & $-2.265 * * *$ & 0.105 \\
\hline $\operatorname{loc} 2$ & $-4.187 * * *$ & 0.088 & $-4.482 * * *$ & 0.360 & $-2.640 * * *$ & 0.073 & $-8.474 * * *$ & 0.223 & $-3.847 * * *$ & 0.083 & $-4.116 * * *$ & 0.403 \\
\hline$q 1$ & 0 & & 0 & & 0 & & 0 & & 0 & & 0 & \\
\hline$q 2$ & $1.161 * * *$ & 0.134 & 0.252 & 0.170 & $0.914 * * *$ & 0.184 & $-0.367 * * *$ & 0.119 & $1.250 * * *$ & 0.157 & 0.164 & 0.174 \\
\hline Loans & \multicolumn{2}{|c|}{21,310} & \multicolumn{2}{|c|}{21,310} & \multicolumn{2}{|c|}{21,310} & \multicolumn{2}{|c|}{21,310} & \multicolumn{2}{|c|}{21,310} & \multicolumn{2}{|c|}{21,310} \\
\hline Obs & \multicolumn{2}{|c|}{909,035} & \multicolumn{2}{|c|}{909,035} & \multicolumn{2}{|c|}{868,413} & \multicolumn{2}{|c|}{909,035} & \multicolumn{2}{|c|}{868,413} & \multicolumn{2}{|c|}{909,035} \\
\hline Loglike & \multicolumn{2}{|c|}{$-77,001$} & \multicolumn{2}{|c|}{$-77,518$} & \multicolumn{2}{|c|}{$-73,907$} & \multicolumn{2}{|c|}{$-76,739$} & \multicolumn{2}{|c|}{$-73,492$} & \multicolumn{2}{|c|}{$-77,520$} \\
\hline
\end{tabular}

Note: * indicates significance at 90 percent, ** indicates significance at 95 percent, and *** indicates significance at 99 percent. $l o c l$ and $l o c 2$ are shift parameters of the two heterogeneity groups. $q 1$ and $q 2$ are logistic transformation parameters for the heterogeneity mass points. $q 1$ is normalized to zero. All unemployment variables are scaled to mean 4.5 and standard deviation 1 for identification. All other variables (other than the interaction terms) are scaled to mean 0 and standard deviation 1. unempr is the observed of county unemployment rate, its HP cyclical component, its BN cyclical component, its HP permanent component, its BN permanent component, and its HP Ranking Score. These specifications are jointly estimated with prepayment (results not shown). 


\section{Figure 1: Observed US Unemployment Rate and Permanent Components}

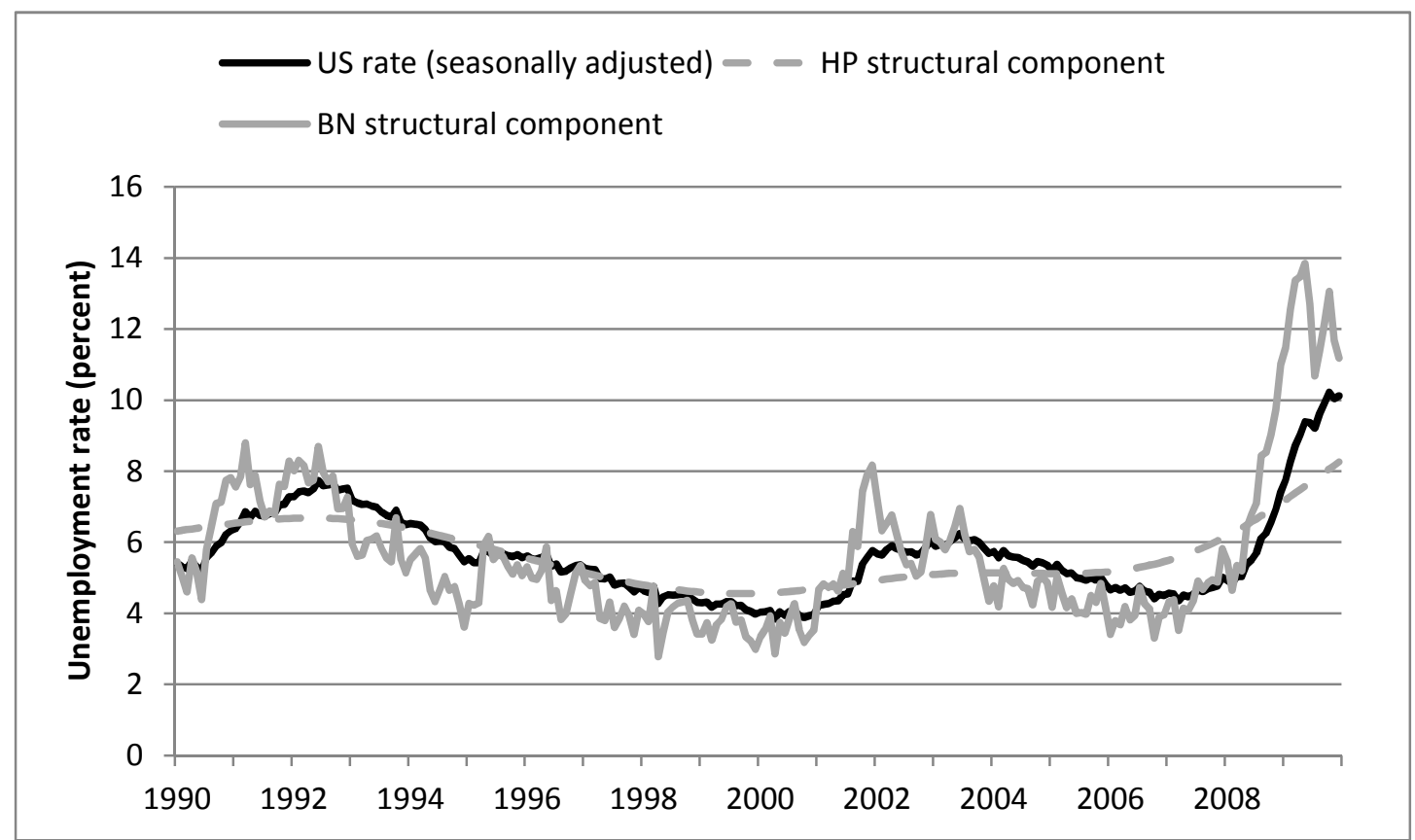

Note: The US unemployment rate is seasonally adjusted using Census X11. BN decomposition is based on $\operatorname{ARMA}(1,2)$ forecasting of first difference and HP filter smoothing parameter is 129,600. 
Figure 2: Non-Parametric Default Hazards

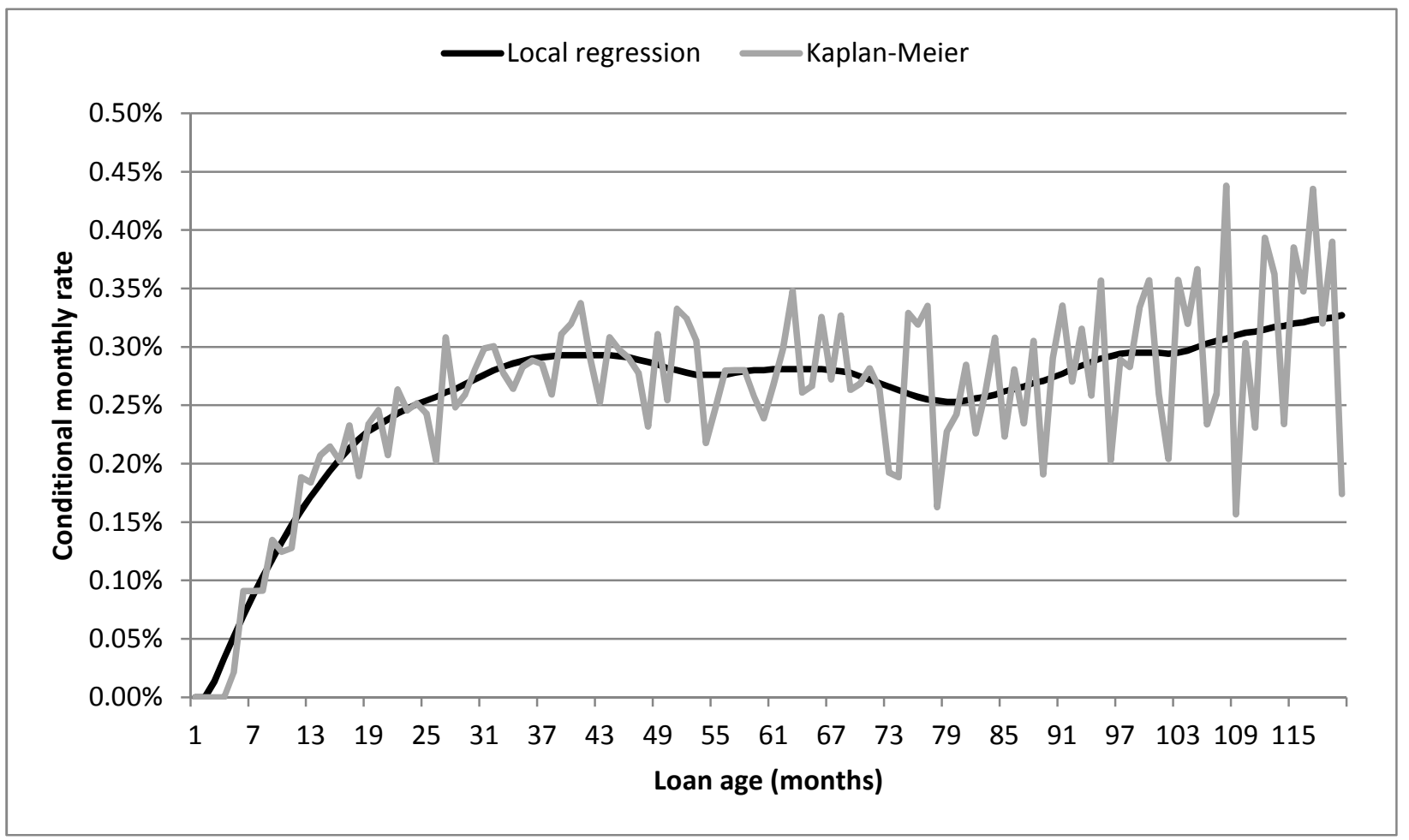


Figure 3: Non-Parametric Prepayment Hazards

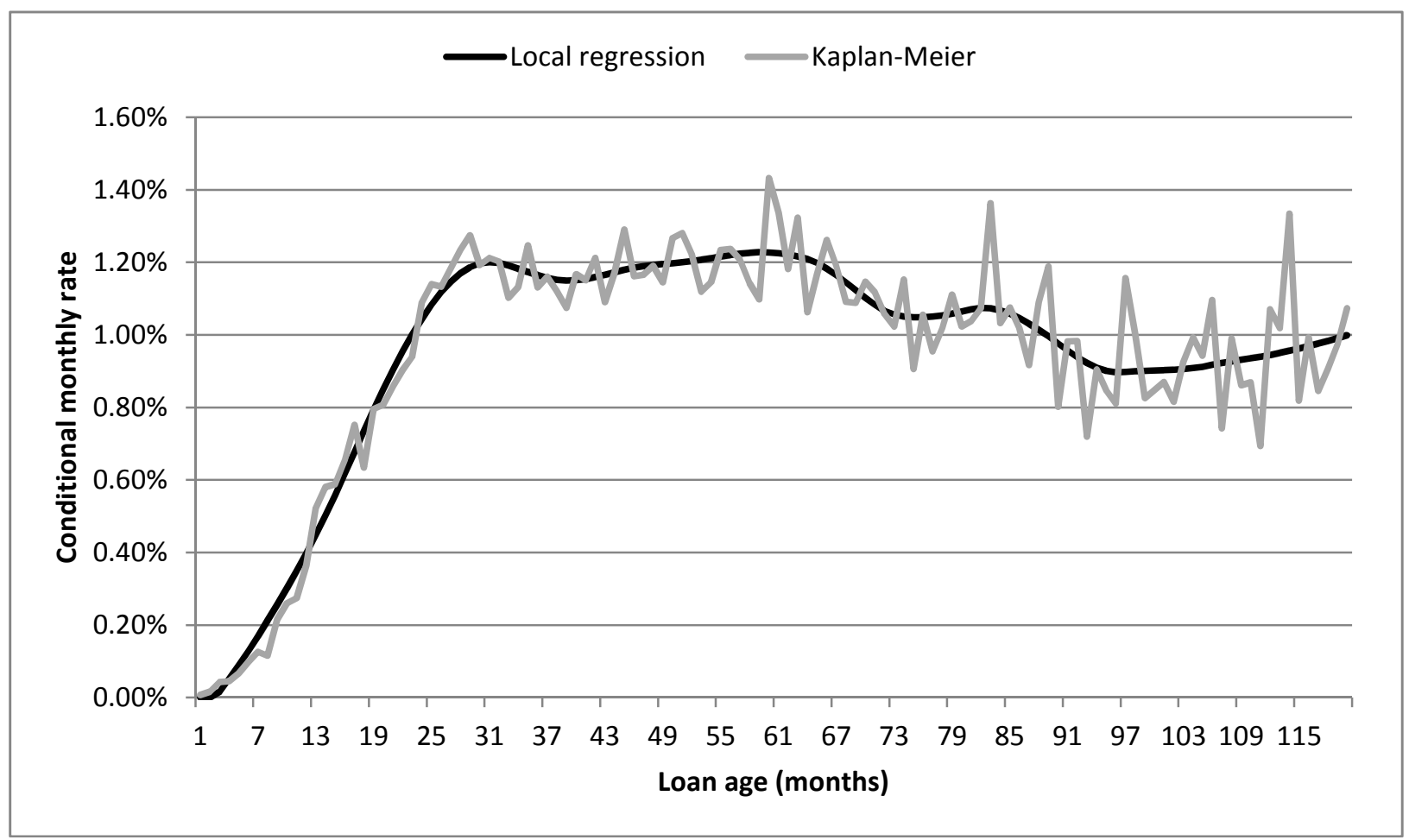




\section{Figure 4: Default and Local Unemployment}

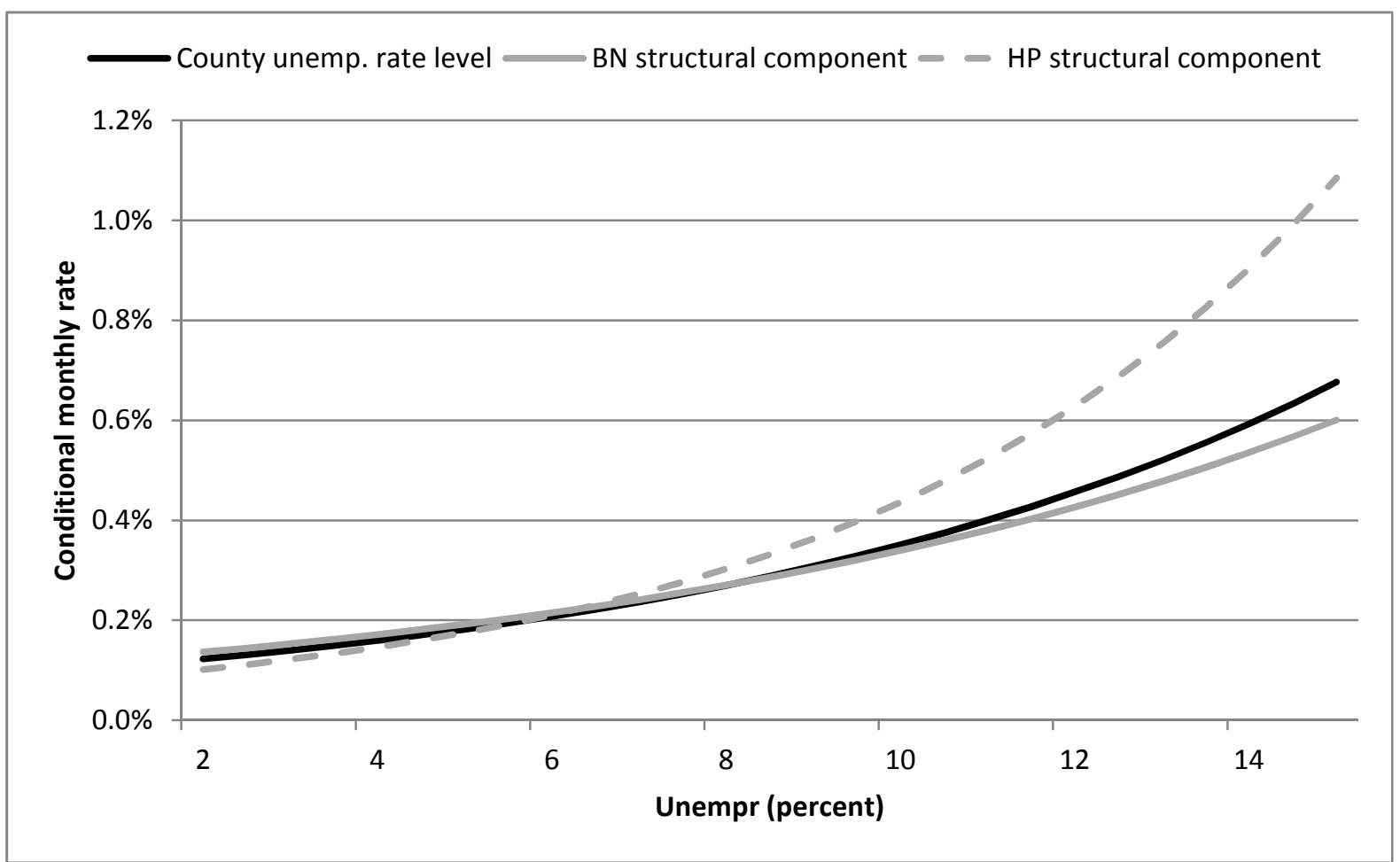

Note: Conditional monthly rate is estimated with sample mean characteristics (other than local unemployment rates). Each series uses individual equation parameter estimates in Table 5 and loan age is set to 37 th month. 
Figure 5: Prepayment and Local Unemployment

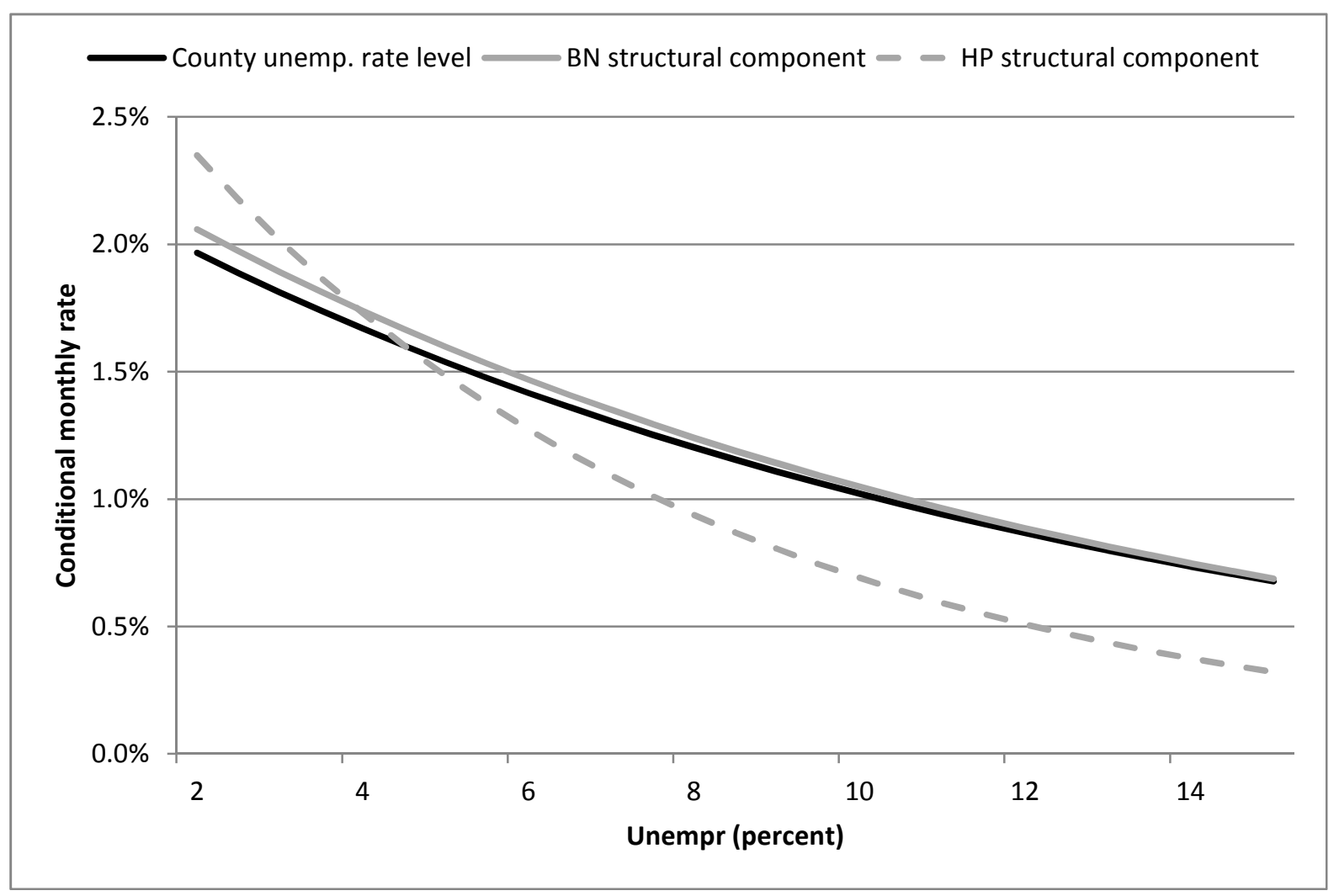

Note: Conditional monthly rate is estimated with sample mean characteristics (other than local unemployment rates). Each series uses individual equation parameter estimates in Table 6 and loan age is set to 37th month. 
Figure 6: Default, Observed Unemployment, and Credit Scores

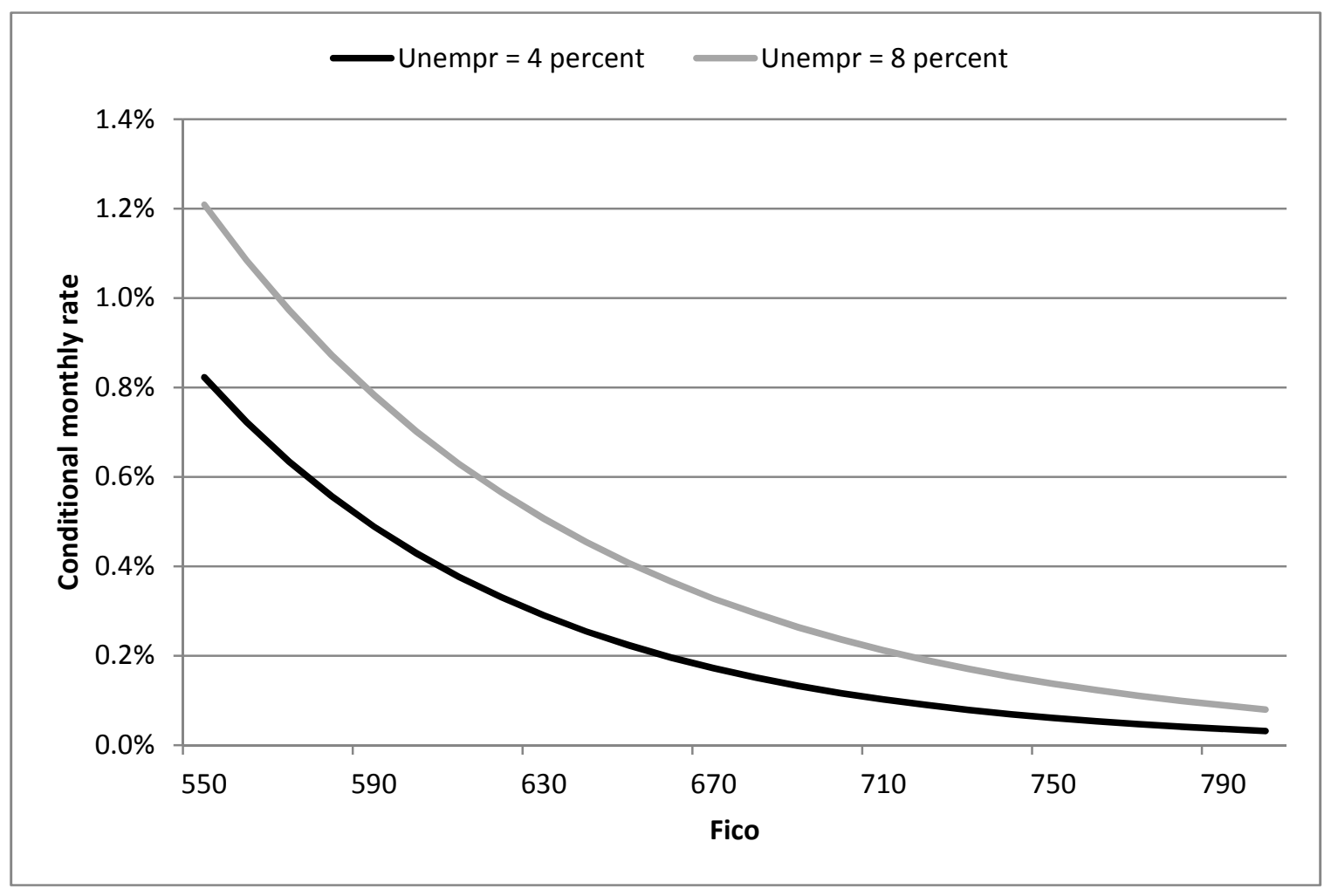

Note: Conditional monthly rate is estimated with sample mean characteristics (other than local unemployment rate and Fico score). Both series use "Observed" equation parameter estimates in Table 7 and loan age is set to 37 th month. The 4 and 8 percent unemployment rates are chosen because they are approximately one standard devaiton from the mean. 
Figure 7: Default, Cyclical HP Unemployment, and Credit Scores

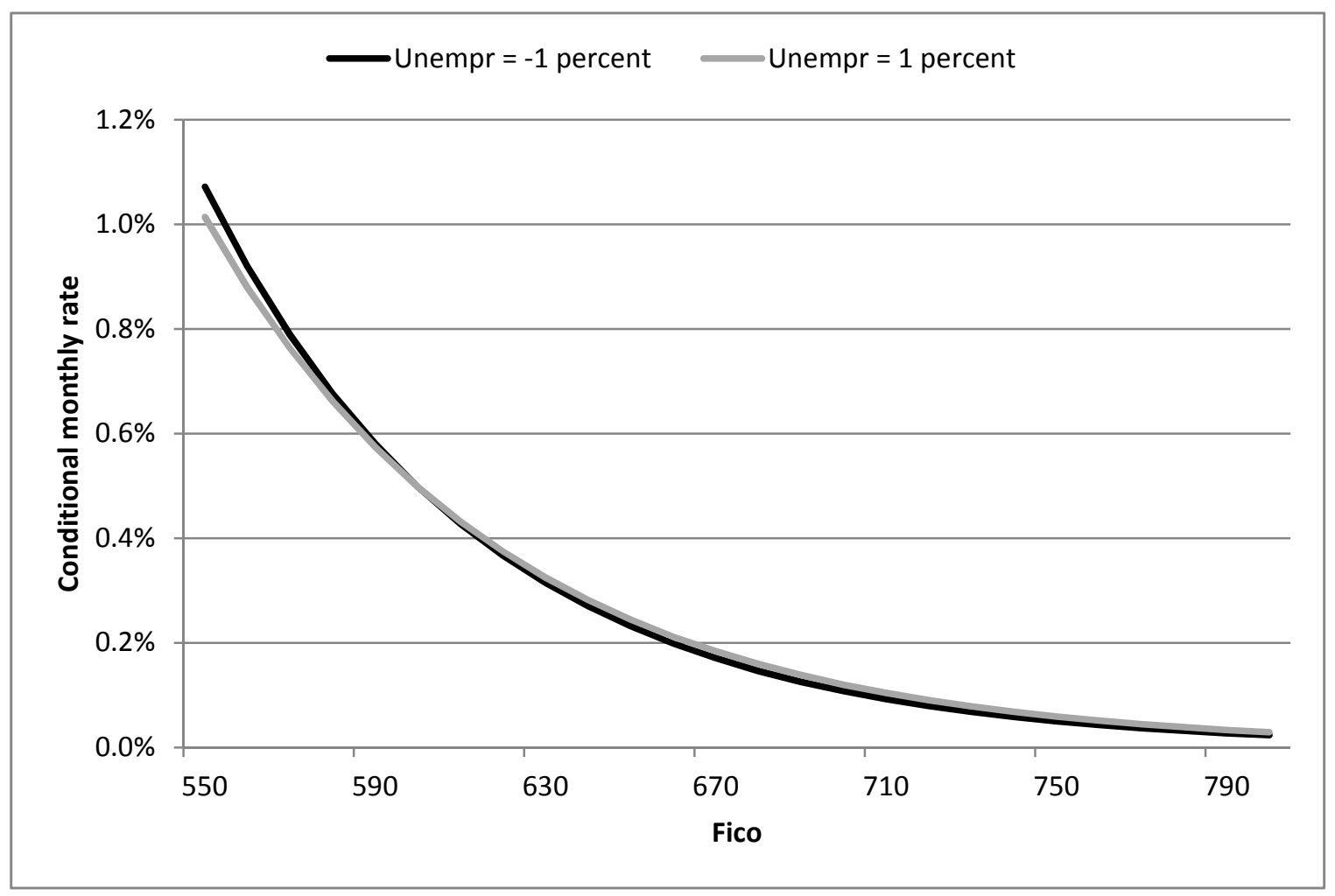

Note: Conditional monthly rate is estimated with sample mean characteristics (other than local unemployment rate and Fico score). Both series use "Cyclical HP" equation parameter estimates in Table 7 and loan age is set to 37 th month. The -1 and 1 percent cyclical compoenent values are chosen because they are one standard devaiton from the mean. 
Figure 8: Default, BN Structural Unemployment, and Credit Scores

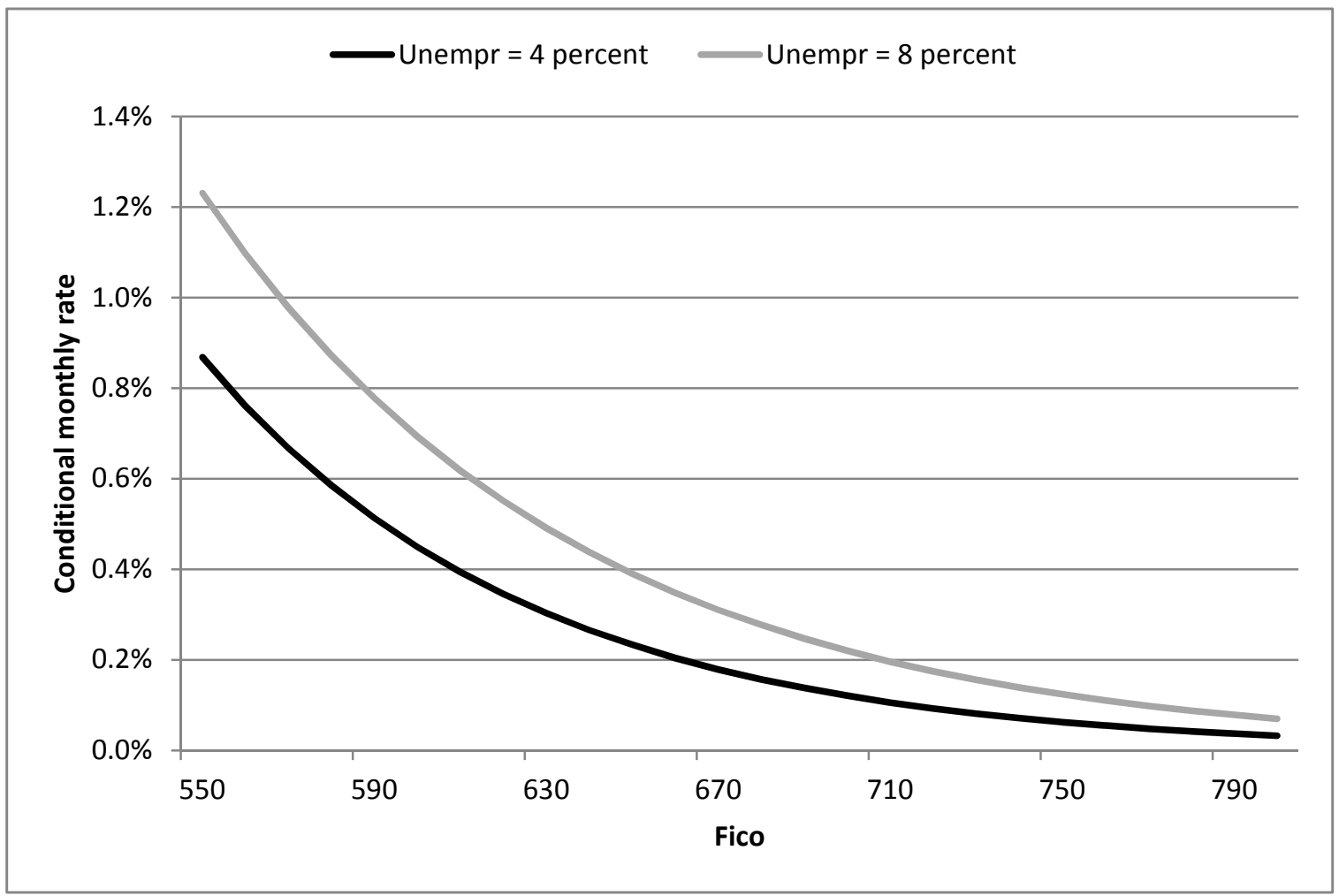

Note: Conditional monthly rate is estimated with sample mean characteristics (other than local unemployment rate and Fico score). Both series use "Structural BN" equation parameter estimates in Table 7 and loan age is set to 37 th month. The 4 and 8 percent unemployment rates are chosen because they are approximately one standard devaiton from the mean. 
Figure 9: Default, Observed Unemployment, and Current LTV

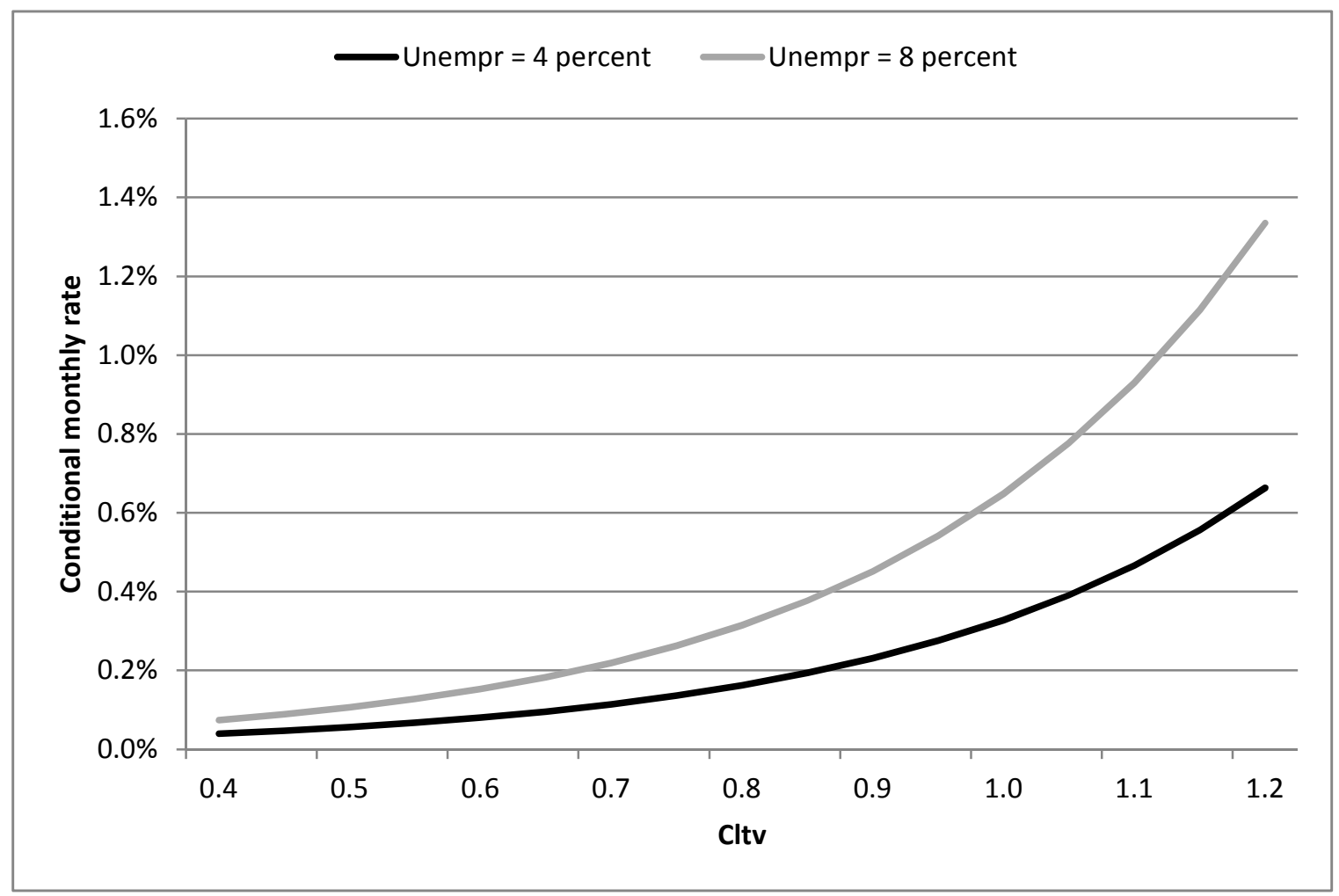

Note: Conditional monthly rate is estimated with sample mean characteristics (other than local unemployment rate and current loan-to-value ratio). Both series use "Observed" equation parameter estimates in Table 7 and loan age is set to 37 th month. The 4 and 8 percent unemployment rates are chosen because they are approximately one standard devaiton from the mean. 


\section{Figure 10: Default, Cyclical HP Unemployment, and Current LTV}

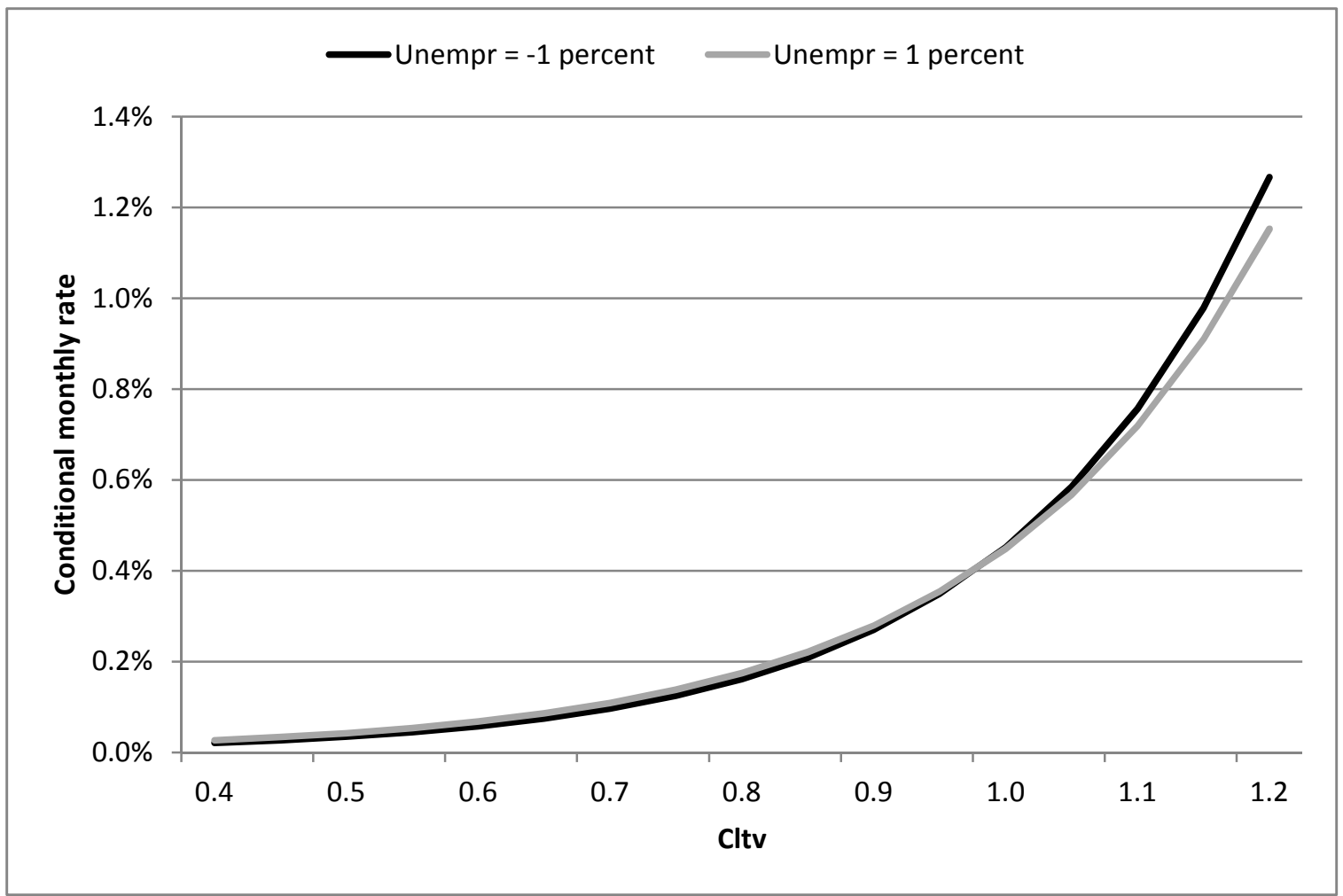

Note: Conditional monthly rate is estimated with sample mean characteristics (other than local unemployment rate and current loan-to-value ratio). Both series use "Cyclical HP" equation parameter estimates in Table 7 and loan age is set to 37 th month. The -1 and 1 percent cyclical compoenent values are chosen because they are one standard devaiton from the mean. 


\section{Figure 11: Default, Cyclical BN Unemployment, and Current LTV}



Note: Conditional monthly rate is estimated with sample mean characteristics (other than local unemployment rate and current loan-to-value ratio). Both series use "Cyclical BN" equation parameter estimates in Table 7 and loan age is set to 37 th month. The -1 and 1 percent cyclical compoenent values are chosen because they are one standard devaiton from the mean. 


\section{Figure 12: Default, HP Structural Unemployment, and Current LTV}

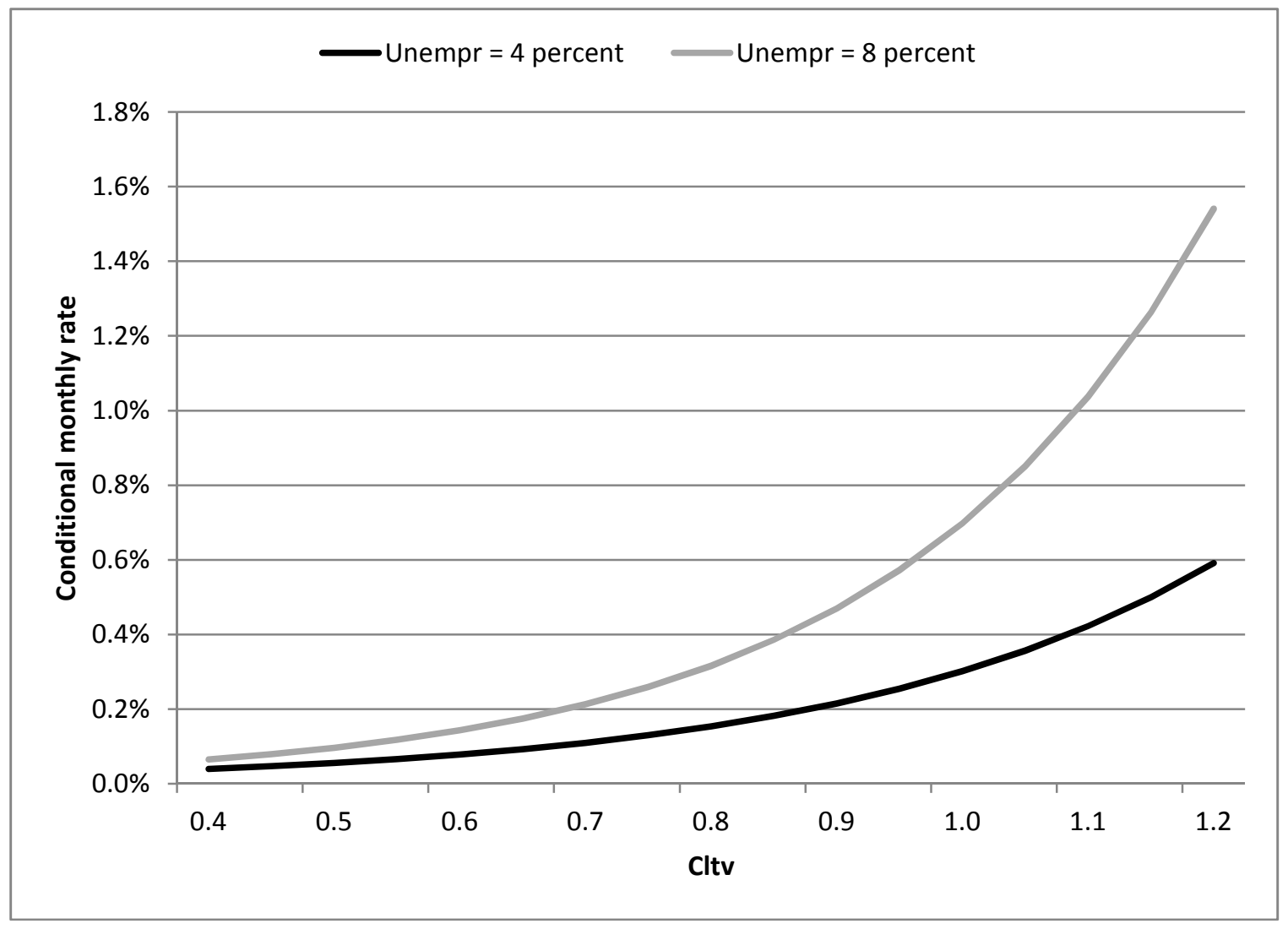

Note: Conditional monthly rate is estimated with sample mean characteristics (other than local unemployment rate and current loan-to-value ratio). Both series use "Structural HP" equation parameter estimates in Table 7 and loan age is set to 37 th month. The 4 and 8 percent unemployment rates are chosen because they are approximately one standard devaiton from the mean. 